\title{
Left Ventricular Hypertrophy and Cerebral Small Vessel Disease: A Systematic Review and Meta-Analysis
}

\author{
Andreas Papadopoulos, ${ }^{\mathrm{a}, *}$ Konstantinos Palaiopanos, ${ }^{\mathrm{a}, *}$ Athanasios P. Protogerou, ${ }^{\mathrm{b}}$ George P. Paraskevas, ${ }^{\mathrm{c}}$ \\ Georgios Tsivgoulis, ${ }^{\mathrm{d}, \mathrm{e}}$ Marios K. Georgakis ${ }^{\mathrm{f}}$ \\ ${ }^{a}$ Medical School, National and Kapodistrian University of Athens, Athens, Greece \\ ${ }^{b}$ Cardiovascular Prevention and Research Unit, Department of Pathophysiology, National and Kapodistrian University of Athens, Athens, Greece

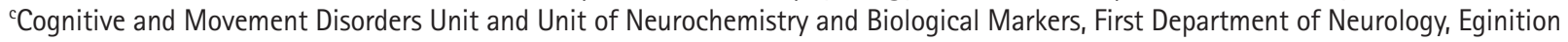 \\ University Hospital, Medical School, National and Kapodistrian University of Athens, Athens, Greece \\ ${ }^{d}$ Second Department of Neurology, Attikon Hospital, School of Medicine, National and Kapodistrian University of Athens, Athens, Greece \\ 'Department of Neurology, University of Tennessee Health Science Center, Memphis, TN, USA \\ fInstitute for Stroke and Dementia Research, LMU University Hospital, Ludwig-Maximilians-University (LMU), Munich, Germany
}

Background and Purpose Left ventricular hypertrophy (LVH) is associated with the risk of stroke and dementia independently of other vascular risk factors, but its association with cerebral small vessel disease (CSVD) remains unknown. Here, we employed a systematic review and meta-analysis to address this gap.

Methods Following the MOOSE guidelines (PROSPERO protocol: CRD42018110305), we systematically searched the literature for studies exploring the association between LVH or left ventricular (LV) mass, with neuroimaging markers of CSVD (lacunes, white matter hyperintensities [WMHs], cerebral microbleeds [CMBs]). We evaluated risk of bias and pooled association estimates with random-effects meta-analyses.

Results We identified 31 studies ( $n=25,562)$ meeting our eligibility criteria. In meta-analysis, LVH was associated with lacunes and extensive WMHs in studies of the general population (odds ratio [OR] lacunes, $1.49 ; 95 \%$ confidence interval $[\mathrm{Cl}], 1.12$ to 2.00$)\left(\mathrm{OR}\right.$ wMH, $_{1} 1.73 ; 95 \% \mathrm{Cl}, 1.38$ to 2.17$)$ and studies in highrisk populations ( $\mathrm{OR}$ lacunes: $2.39 ; 95 \% \mathrm{Cl}, 1.32$ to 4.32$)\left(\mathrm{OR}_{w M H}, 2.01 ; 95 \% \mathrm{Cl}, 1.45\right.$ to 2.80$)$. The results remained stable in general population studies adjusting for hypertension and other vascular risk factors, as well as in sub-analyses by LVH assessment method (echocardiography/electrocardiogram), study design (cross-sectional/cohort), and study quality. Across LV morphology patterns, we found gradually increasing ORs for concentric remodelling, eccentric hypertrophy, and concentric hypertrophy, as compared to normal LV geometry. LVH was further associated with CMBs in high-risk population studies. Conclusions LVH is associated with neuroimaging markers of CSVD independently of hypertension and other vascular risk factors. Our findings suggest LVH as a novel risk factor for CSVD and highlight the link between subclinical heart and brain damage.

Keywords Hypertrophy, left ventricular; Cerebral small vessel diseases; Stroke, lacunar; Leukoaraiosis; Cerebral hemorrhage; Meta-analysis
Correspondence: Marios K. Georgakis Institute for Stroke and Dementia Research, LMU University Hospital, Ludwig-Maximilians-University (LMU), Feodor-Lynen-Str. 17, 81377 Munich, Germany

Tel: +49-89-4400-46126

Fax: +49-89-4400-46040

E-mail: marios.georgakis@med.uni-muenchen.de

Received: November 27, 2019

Revised: January 9, 2020

Accepted: March 6, 2020

*These authors contributed equally to the manuscript as first author. 


\section{Introduction}

Cerebral small vessel disease (CSVD) describes any pathological processes affecting the perforating arterioles, capillaries, and venules of the brain. ${ }^{1,2}$ CSVD is the leading cause of vascular cognitive impairment, ${ }_{1}^{3}$ accounts for $25 \%$ of all ischemic strokes ${ }^{4}$ and the majority of intracerebral hemorrhage cases, ${ }^{5}$ and is an independent predictor of mortality. ${ }^{6.7}$ Manifestations of CSVD are further associated with physical and psychological sequalae in the elderly including gait, ${ }^{8}$ functional, ${ }^{9}$ and mood $^{10}$ disturbances. CSVD can be defined by neuroimaging markers including lacunes, white matter hyperintensities (WMHs), cerebral microbleeds (CMBs) and enlarged perivascular spaces (EPVSs). ${ }^{11}$ Despite the very high prevalence of CSVD in the ageing population ( $\geq 90 \%$ in individuals $\geq 65$ years $^{12}$ ), the underlying mechanisms are incompletely understood, thus impeding the development of effective prevention strategies.

Left ventricular hypertrophy (LVH), a pathological increase in left ventricular mass (LVM), ${ }^{13}$ has been proposed as an independent risk factor for cardiovascular disease ${ }^{14}$ and is included in the original 10-year Framingham stroke risk score for incident stroke prediction in the elderly. ${ }^{15} \mathrm{LVH}$ and increased LVM are clinical markers of hypertension-mediated organ damage and constitute surrogate indicators of the duration of exposure to hypertension and other vascular risk factors. ${ }^{14}$ In large-scale population-based cohort studies, LVH and increased LVM have been associated with the risk of incident stroke in the elderly, independently of hypertension presence or duration and other traditional vascular risk factors. ${ }^{16-18}$ Furthermore, in a recent meta-analysis, we showed similar associations of LVH with cognitive decline and risk of incident dementia in both the general and high-risk populations. ${ }^{19}$

These associations could be explained by effects of LVH on the microvasculature. Although several studies explore the associations between LVH or increased LVM and subclinical neuroimaging markers of $\mathrm{CSVD}_{1}{ }^{20-22}$ the results vary widely, probably because of heterogeneity in the populations examined, small sample sizes, variable methodologies for LVH assessment or LVM indexing, and differences in CSVD neuroimaging definitions. Furthermore, the studies differ regarding their methods for adjustment for hypertension and other vascular risk factors. Hence, it remains unknown if LVH is independently associated with subclinical CSVD neuroimaging markers.

Here, we leveraged data from published literature and performed a systematic review of studies exploring associations between LVH with neuroimaging markers of CSVD, aiming to: (1) critically evaluate the methodology of the included studies and identify limitations of the existing literature; (2) quantify in meta-analyses the associations of LVH and LVM with lacunes, WMHs, CMBs, and EPVSs in general population and highrisk individuals; and (3) explore if these associations are independent of the presence and/or duration of hypertension and other vascular risk factors.

\section{Methods}

This systematic review was based on a predefined protocol registered to PROSPERO (30 October 2018, registration number: CRD42018110305, available from: http://www.crd.york.ac.uk/ PROSPERO/display_record.php?ID=CRD42018110305), compliant with the Meta-analysis of Observational Studies in Epidemiology (MOOSE) guidelines. ${ }^{23}$

\section{Literature search}

Two independent reviewers (A.P. and K.P.) systematically screened the Medline (through PubMed), Scopus and Cochrane databases from inception to December 28, 2019 to identify studies investigating the association between LVH and CSVD neuroimaging markers. The detailed search strategy is available in the Supplement (Supplementary methods). All reference lists of the derived eligible articles were hand-searched for potential eligible studies not identified through the database search ("snowball" procedure). No language or publication year restrictions were applied. Eligible studies were evaluated for possible population overlap according to geographical setting, chronological period, sample size, outcome under study, and type of statistical analysis. In case of overlap, we opted for the most recent study. We further contacted the corresponding authors of articles presenting evidence that relevant data were available but not quantifying the associations under study, in order to request supplementary analyses. Differences between the two reviewers were solved through team consensus.

\section{Eligibility criteria}

We considered as eligible cohort, cross-sectional, and casecontrol studies, as well as secondary analyses of randomized controlled trials exploring the association between LVH and neuroimaging markers of CSVD. Cases series, case reports, systematic or narrative reviews, animal and in vitro studies were excluded. We included studies of the general population or studies focused on specific high-risk populations, such as patients with stroke, hypertension, cardiovascular disease, diabetes mellitus, and chronic kidney disease. All analyses were performed separately for the general population and high-risk population studies. We excluded studies examining populations with genetic diseases predisposing to CSVD (e.g., Cerebral Au- 
tosomal Dominant/Recessive Arteriopathy with Subcortical Infarcts and Leukoencephalopathy [CADASIL, CARASIL], Fabry disease), autoimmune diseases and vasculitis, primary cardiomyopathies (e.g., dilatative or hypertrophic) and those including solely dementia individuals. Studies without a non-LVH comparison group were also excluded.

The exposure variables of interest included: (1) dichotomously defined LVH, diagnosed by electrocardiography (ECG), transthoracic echocardiography (TTE), or cardiac magnetic resonance imaging (MRI), and (2) continuous LVM measures, indexed (LVMI) or not to body surface area, assessed by TTE or cardiac MRI. For TTE-assessed LVH, we preferably included studies defining $L V H$ as $L V M \geq 115 \mathrm{~g} / \mathrm{m}^{2}$ in males and $\geq 95 \mathrm{~g} / \mathrm{m}^{2}$ in females, ${ }^{13}$ but other cut-off points were also considered. ECG-assessed LVH should be defined by validated (e.g., Sokolow-Lyon indices or Cornell voltage criteria) ${ }^{24,25}$ methods in standard 7 or 12-lead ECG. LVM should be calculated by TTE parameters according to the method of Devereux et al. ${ }^{26}$

The primary outcomes of our study included the following neuroimaging markers of CSVD, in accordance with the STandards for ReportIng Vascular changes on nEuroimaging (STRIVE ${ }^{11}$ ): lacunes, WMHs, CMBs, and EPVSs. Eligible were considered MRI or computed tomography (CT) studies assessing lacunes and $\mathrm{WMHs}$, as previous literature has described compliance validity between the two methods, ${ }_{1}^{27,28}$ and MRI studies evaluating CMBs and EPVSs. We included studies defining lacunes as round or ovoid, subcortical, fluid-filled cavities, measuring between 3 and $15-\mathrm{mm}$ in maximal diameter, consistent with a previous acute small deep brain infarct or hemorrhage in the territory of one perforating arteriole. Studies exploring lacunar strokes, defined as lacunes with acute clinical manifestations, were also included. We further post hoc decided to include studies examining "silent infarcts" provided that $>80 \%$ of the included events were lacunes. WMHs should be identified as hyperintense areas on T2-weighted MRI sequences, isointense or hypointense on fluid-attenuated inversion recovery (FLAIR) imaging or as CT hypodensities. The studies should assess WMHs presence or severity through semiquantitative visual rating scales (e.g., Fazekas) or WMH volume via automated or semi-automated methods. Due to the high prevalence of WMHs in the elderly, ${ }^{12}$ the individual studies dichotomized WMH outcome based on specific burden levels (either based on a scale or a volumetric measurement) instead of mere presence. For simplicity, we use the term "extensive WMHs" to refer to this outcome although the individual studies used different methods for its assessment. CMBs had to be visualized as small $(\leq 10 \mathrm{~mm})$ areas of signal void with associated blooming on T2*-weighted MRI sequences. EPVSs should be defined as fluid-filled spaces following the course of a vessel with cerebrospinal fluid-like signal intensity.

\section{Data extraction}

A predefined spreadsheet was used to extract the following data: publication details (authors, year), study information (geographical region, recruitment period, design, population under study, sample size, follow-up parameters), study sample characteristics (age, gender, smoking, body mass index, hypertension history, diabetes mellitus, stroke, coronary artery disease), LVH/LVMI ascertainment (assessment method, definition, method/scale of quantification), CSVD assessment (marker under study, imaging modality, definition, method/scale of quantification, number of cases), and statistical analysis details (analysis type, effect estimates, 95\% confidence intervals [Cls], adjusting variables). The corresponding author was contacted in case of missing data.

\section{Quality assessment}

We evaluated studies for risk of bias using the Newcastle-0ttawa scale. ${ }^{29}$ As the vast majority of eligible studies were of cross-sectional or cohort design, we applied the nine-item cohort subscale to all studies. The following criteria were assessed: representativeness of the exposed population; selection of the non-exposed group; LVH ascertainment; outcome absence at study onset; comparability of the exposed and nonexposed group for age and hypertension; CSVD markers assessment; follow-up period length and completion. Cross-sectional studies, by definition, did not receive any points for longitudinal assessment items (outcome absence at study onset, followup period length and completion). The detailed pre-defined handling of each criterion for the purposes of this systematic review is outlined in the Supplementary Table 1.

\section{Statistical analysis}

For each eligible study, we extracted association estimates and 95\% Cls between presence of LVH and presence or incidence of neuroimaging CSVD markers. In 21 out of the 27 studies in our meta-analysis, the association estimates were odds ratios (ORs) derived from logistic regression analyses. Two prospective studies presented relative risks (RRs), but as the prevalence of the examined outcome was $<10 \%$ in their population we considered RRs to be comparable to $\mathrm{ORs}^{30}$ and pooled them with the other studies. Where ORs were not presented, we handcalculated unadjusted ORs using $2 \times 2$ tables, based on data from the published articles. In studies presenting only ORs stratified by LVMI increments, we obtained the OR for the presence or absence of LVH by applying the method described 
by Hamling et al. ${ }^{31}$ For studies examining WMH volume or WMH severity measured as continuous outcomes, we transformed the presented beta coefficients to standardized mean differences and then used the latter to estimate the $O R$ for a dichotomized WMH measure, based on validated formulae with the use of an online tool (https://campbellcollaboration. org/research-resources/effect-size-calculator.html). ${ }^{32}$

We then performed random-effects meta-analyses of the derived association estimates to obtain pooled ORs and 95\% $\mathrm{Cls}$ for each outcome. The method described by DerSimonian and Laird ${ }^{33}$ was our primary meta-analytical approach. For our main analyses we also performed alternative random-effects meta-analytical approaches (ORs calculated via the Paule-Mandel between-study variance estimator, ${ }^{34}$ 95\% $\mathrm{Cls}$ with the Hartung-Knapp ${ }^{35}$ and modified Hartung-Knapp ${ }^{36}$ methods), as detailed in the supplement (Supplementary methods). ${ }^{34,36-46}$ All analyses were performed separately for the general population and high-risk population studies. The presence of heterogeneity was evaluated by the $\mathrm{I}^{2}$ and the Cochran 0 statistics. We defined low, moderate and high heterogeneity as an $\mathrm{I}^{2}$ of $<25 \%, 25 \%$ to $75 \%$, and $>75 \%$, respectively (significance threshold: $P<0.10){ }^{47}$ To explore potential sources of heterogeneity, we performed sensitivity and subgroup analyses stratified by study design (cross-sectional, cohort), LVH assess- ment method (TTE, ECG), LVH definition criteria (ECG: only $\uparrow$ QRS voltage-based criteria; TEE: LVMI $\geq 115 \mathrm{~g} / \mathrm{m}^{2}$ in males and $\geq 95 \mathrm{~g} / \mathrm{m}^{2}$ in females, body surface indexed), CSVD assessment method (MRI, CT), level of adjustment (studies adjusted for age, sex, hypertension, and other vascular risk factors), and fulfilment of the quality criteria of the Newcastle-Ottawa scale. Where possible, we further performed analyses for different left ventricular (LV) morphology patterns: normal LV geometry, concentric remodeling, eccentric hypertrophy, and concentric hypertrophy. ${ }^{13}$ In order to explore the effect of each individual study in the overall estimate we conducted "leaveone-out" sensitivity analyses.

The results of our main analyses were graphically presented with funnel plots. The effect of potential publication bias (small-study effects) was explored in cases of $\geq 10$ pooled studies using the Egger's test (significance threshold: $P<0.10){ }^{48} \mathrm{In}$ case of statistically significant small-study effects, we adjusted the pooled effect estimates for publication bias using a "trim and fill" analysis. ${ }^{49}$

Statistical significance for the main analyses was set at a two-sided $P<0.05$. All analyses were conducted with the STATA Software version 13.0 (Stata Corporation, College Station, TX, USA).

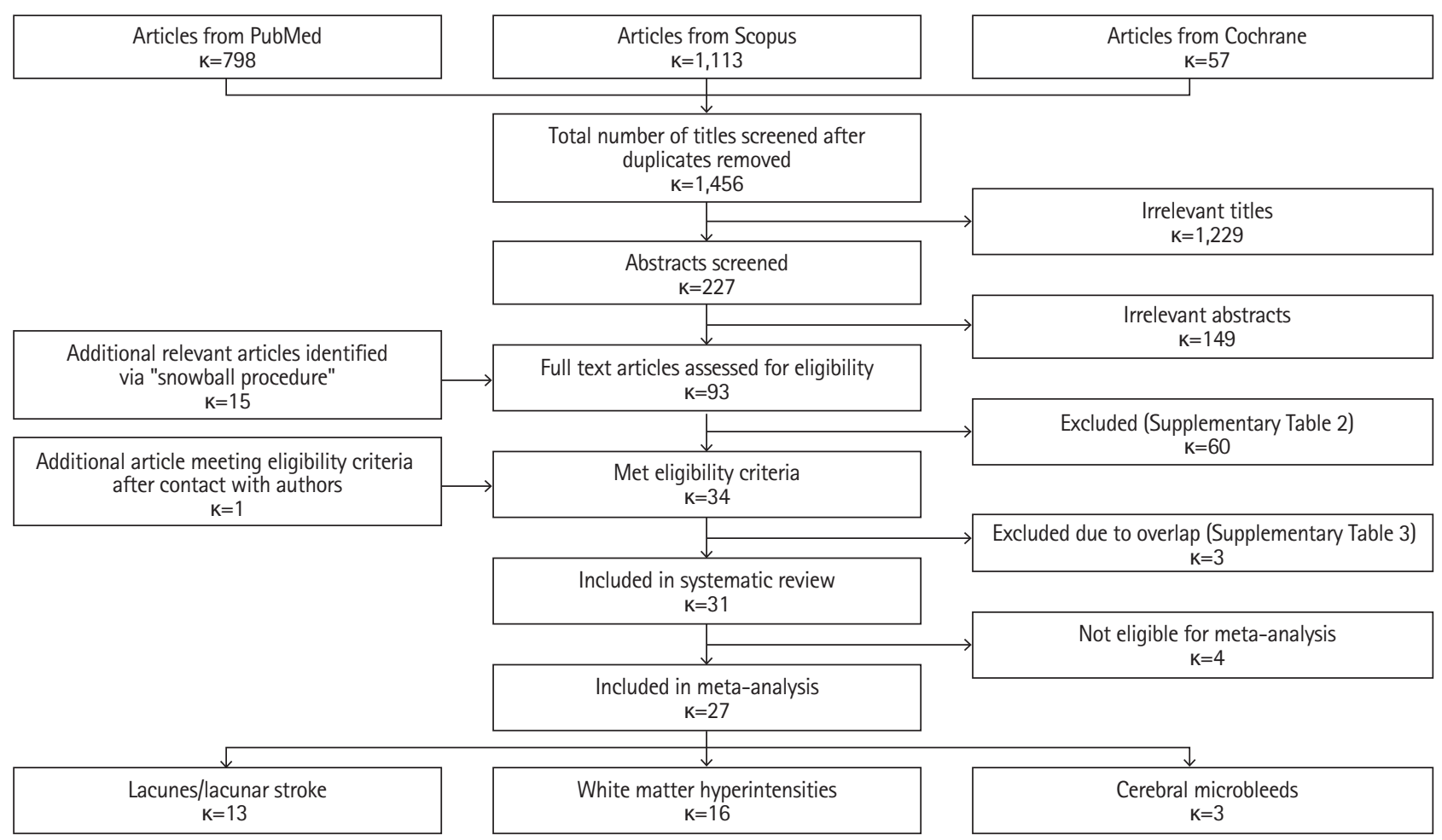

Figure 1. Flowchart of the study selection process. The included articles for each of the outcomes do not sum up to the total number of included articles because several studies provided data for more than one outcome. 


\section{Results}

\section{Review of literature}

Figure 1 summarizes the study selection process. Following screening of 1,456 articles yielded by the literature search, we identified 34 articles meeting our eligibility criteria (60 studies were excluded after full-text screening as described in Supplementary Table 2). Three of them were excluded due to population overlap (Supplementary Table 3). ${ }^{50-52}$ Of the 31 studies $^{20-22,53-80}(n=25,562)$ included in our systematic review, only $27^{21,22,53-60,62-69,72-80}(n=21,010)$ provided appropriate data to also be used in the meta-analysis. Quantitative synthesis of articles examining associations between LVMI and WMH severity or volume as continuous variables was not possible because of the highly heterogeneous statistical methodologies. Of the studies included in meta-analysis, 13 examined presence of lacunes, 16 assessed extensive WMHs and three examined presence of CMBs. No eligible articles investigating EPVSs were identified.

\section{Study characteristics}

The descriptive characteristics of the included studies are presented in Table 1.

\section{Assessment of left ventricular hypertrophy}

The most commonly used definition for ECG-based diagnosis of LVH was the Sokolo-Lyon and/or Cornell definition, but some older studies ${ }^{56,57,65-67,77}$ considered isolated QRS changes "normal" and defined LVH only if additional ST-segment and/or T-wave changes were present. Regarding TTE-defined LVH, the diagnosis was usually made according to internationally accepted standards, i.e., LVMI $\geq 115 \mathrm{~g} / \mathrm{m}^{2}$ for men and $\geq 95 \mathrm{~g} / \mathrm{m}^{2}$ for women (indexed to body surface area). Some studies, however, used different cut-off points, ${ }^{55,68,69,78}$ no indexing $(\mathrm{g})_{1}^{71}$ or height-based indexes (e.g., $\left.g / \mathrm{m}^{2.7}\right) .^{59,72,76}$ Six studies $(n=1,279)^{22,53,68,72,76,78}$ also evaluated LV morphology, classifying it as normal LV geometry, concentric remodeling, eccentric hypertrophy, or concentric hypertrophy.

\section{Lacunes}

Of the 13 studies $21,22,56,57,64,65,67,68,73,74,76,79,80$ examining lacunes $(n=13,529)$, nine were of cross-sectional $(n=6,272)$, three of cohort $(n=7,020)$, and one of case-control $(n=237)$ design. Overall, lacunes were identified in 1,588 individuals. Five of the studies $(n=6,650)$ were based on the general population and the remaining eight $(n=6,879)$ on high-risk population subsets. Mean age of all the individuals was 67 years (range, 57 to 76). Lacunes were assessed by MRI in eight studies $(n=6,091)$, by CT in two $(n=844)$, whereas the three studies examining clinically manifest lacunar stroke utilized either MRI or CT $(n=6,594)$.

\section{White matter hyperintensities}

Twenty-two studies ${ }^{20-22,53-55,58,59,61-64,66,68-72,75,77,78,80}$ investigated WMHs $(n=15,636)$. In 14 of these studies $(n=8,540)$ the outcome was presence of extensive WMHs, whereas six studies $(n=6,319)$ examined WMHs severity or volume as continuous outcomes. Two studies $(n=777)$ presented both types of data. Eighteen studies were of cross-sectional $(n=13,494)$ and three of cohort design $(n=2,011)$, whereas one study presented both a cross-sectional $(n=131)$ and a cohort analysis $(n=113)$. Overall, nine of the studies $(n=10,432)$ were based on the general population and the remaining $13(n=5,204)$ on high-risk population subsets. Mean age of all individuals was 65 years (range, 30 to 76). WMHs were assessed by MRI in 21 studies $(n=15,026)$ and CT in one $(n=610)$. Presence of extensive WMHs was defined by the Fazekas-scale in seven studies $(n=816)$. There was, however, heterogeneity regarding the cutoff point used to define extensive WMHs as well as the location of WMHs assessment (periventricular, deep, or both). Regarding continuous WMH data, either semi-quantitative scales were used to assess WMH severity, or semi-automated and automated computer-based algorithms calculated WMH volume. Two recent studies ${ }^{20,54}$ examined the association between LVMI and diffusion tensor imaging parameters of WM integrity.

\section{Cerebral microbleeds}

All three studies ${ }^{60,63,69}(n=493)$ examining presence of CMBs were of cross-sectional design and based on high-risk population subsets. CMBs were identified in 151 individuals. Mean age of all the individuals was 63 years (range, 52 to 72). All studies utilized the same MRI-based definition.

\section{Quality assessment of included studies}

The overall study quality was moderate. Only one study ${ }^{79}(3 \%)$ fulfilled all nine criteria of the Newcastle-Ottawa scale (Supplementary Table 4). The median quality score was 5/9 for studies examining lacunes and WMHs and 4/9 for those examining CMBs. This could be explained by the cross-sectional design employed by 25 studies (81\%), thus inherently limiting their maximum score to 6/9. Furthermore, only 10 studies (32\%) were based on the general population, thus fulfilling the representativeness of the exposed cohort criterion. Most studies fulfilled the criteria for exposure and outcome assessment methods (87\% and 94\%, respectively), despite the between-study heterogeneity. Regarding the comparability criteria for age and hypertension, 15 (49\%) studies controlled for both, 10 (32\%) 


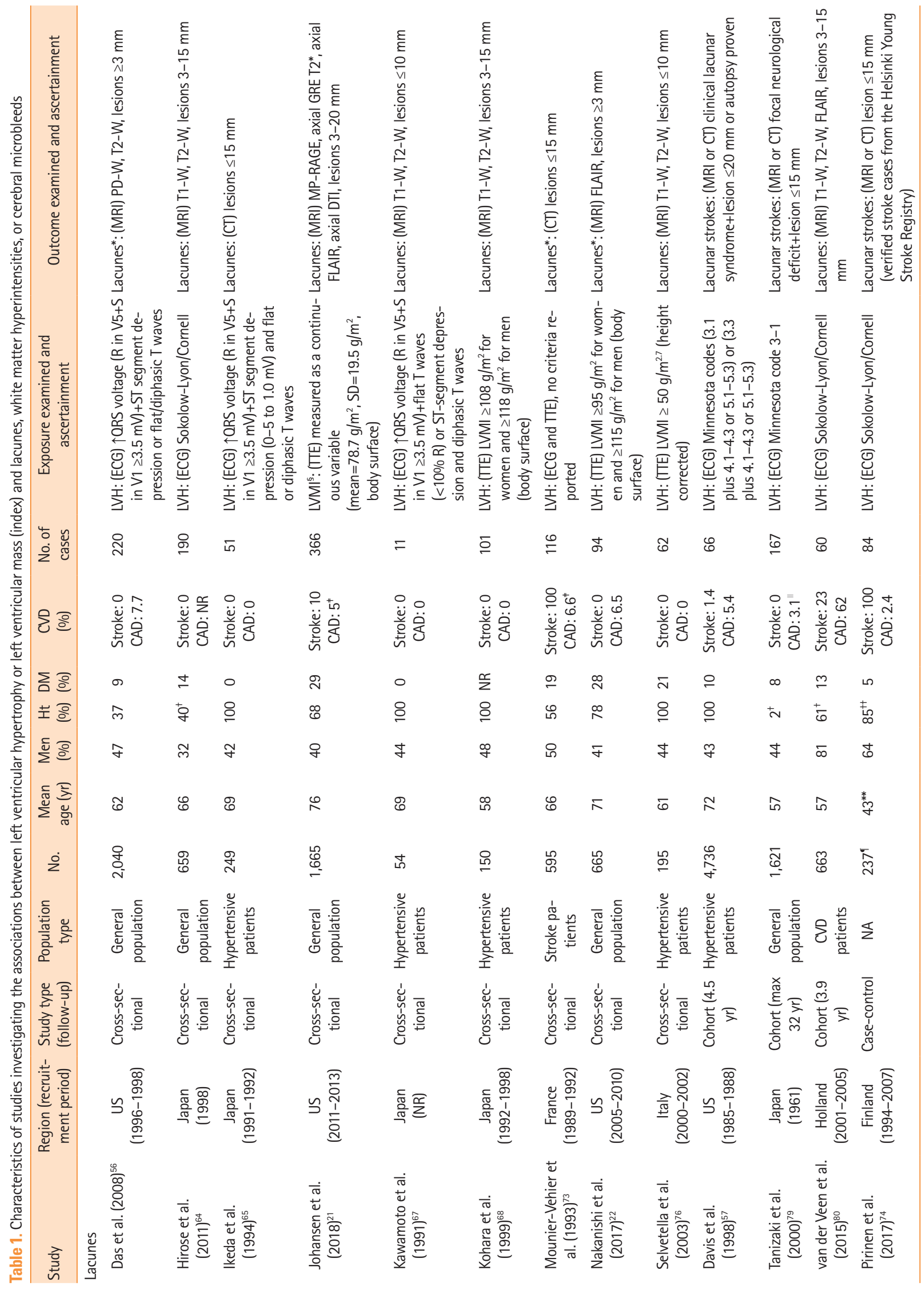




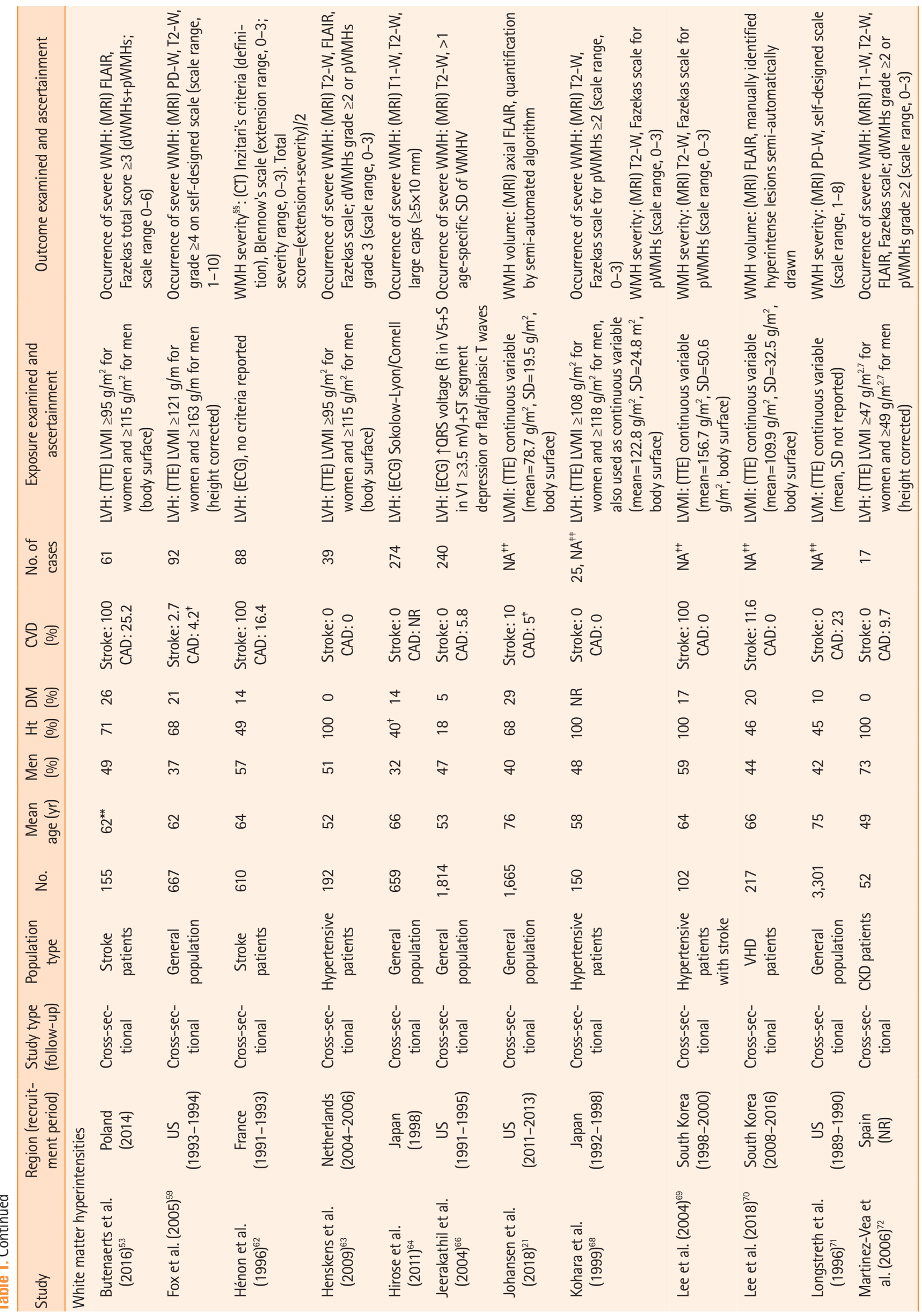




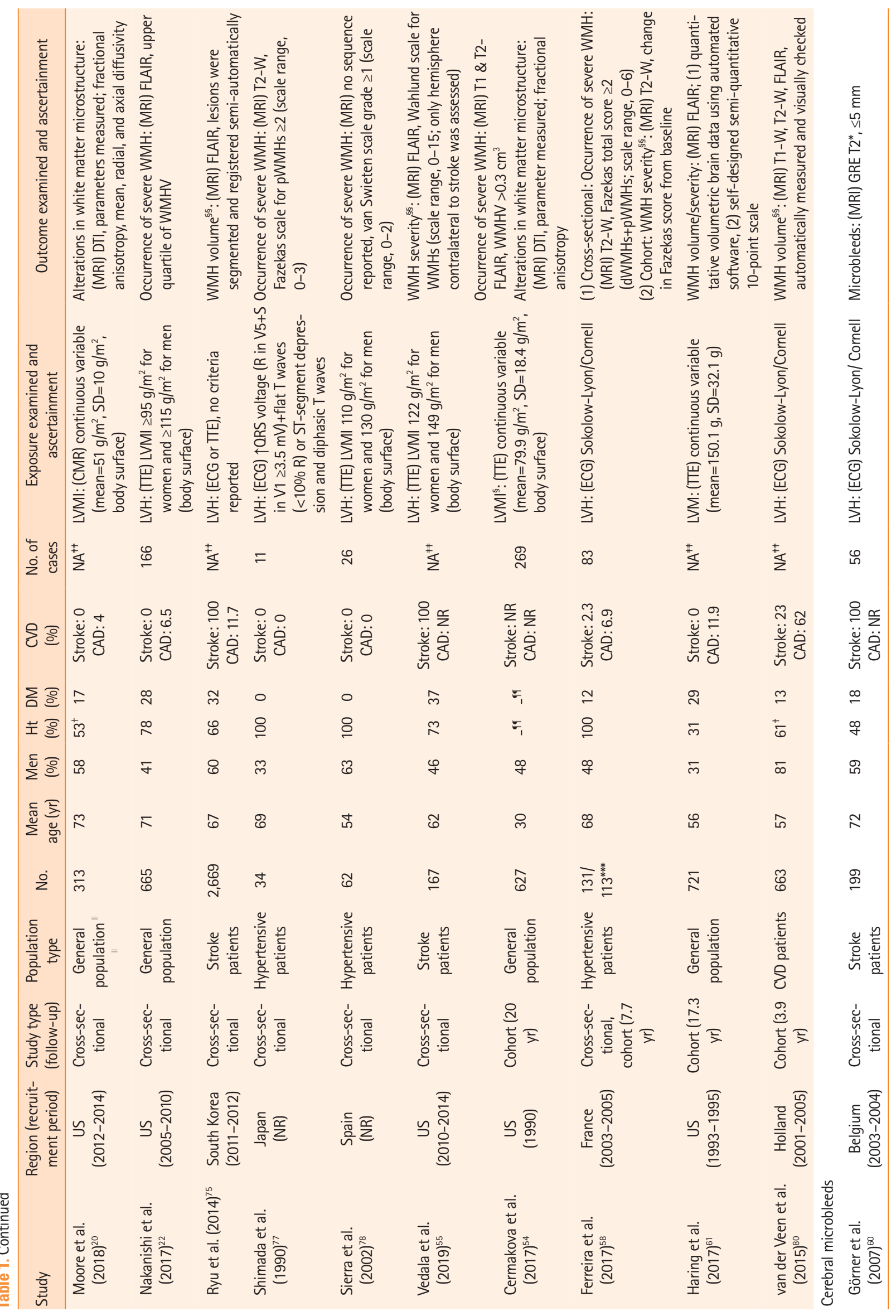




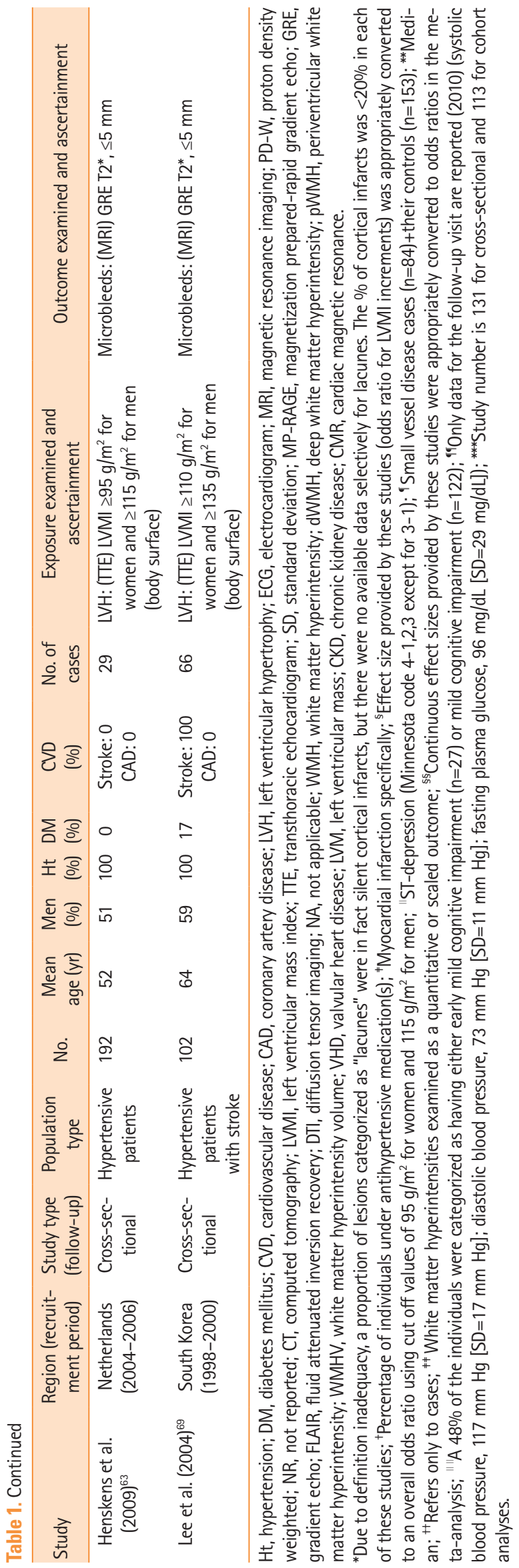

controlled for age but not hypertension, while only six studies (19\%) presented unadjusted results. Lastly, concerning the cohort-specific criteria, three of the six cohort studies assessed CSVD markers at study onset, all six had follow-ups longer than 3 years, and attrition rates were $<20 \%$ for three studies.

\section{Meta-analysis: associations between LVH and CSVD}

In studies of the general population we found presence of LVH to be associated with the odds of lacunes (OR, 1.49; $95 \% \mathrm{Cl}$, 1.12 to 2.00; five studies; 6,650 individuals; 1,037 cases) and extensive WMHs (OR, 1.73; 95\% Cl, 1.38 to 2.17; five studies; 4,432 individuals) (Figure 2). Similar results were also obtained from studies in high-risk populations (lacunes: OR, 2.39; 95\% $\mathrm{Cl}, 1.32$ to 4.32 ; eight studies; 6,879 individuals; 551 cases) (extensive WMHs: OR, 2.01; 95\% Cl, 1.45 to 2.80; 11 studies; 4,885 individuals) (Figure 2). A meta-analysis of the three highrisk population studies with data on $\mathrm{CMBs}$ also showed a significant association between LVH and presence of CMBs (OR, 2.54; $95 \% \mathrm{Cl}, 1.04$ to 6.22 ; three studies; 493 individuals; 151 cases) (Supplementary Figure 1). When using various alternative meta-analytical approaches the associations for lacunes and extensive WMHs remained statistically significant, indicating the robustness of our findings (Supplementary Table 5).

Of note, the results for lacunes and extensive WMHs in the general population were also stable across studies adjusting their analyses for hypertension and other vascular risk factors on top of age and sex (lacunes: adjusted OR, 1.50;95\% Cl, 1.09 to 2.06) (extensive WMHs: adjusted OR, 1.74; $95 \% \mathrm{Cl}$, 1.34 to 2.25 ) (Figure 3).

When exploring LV geometry patterns and LVH subtypes, we documented different magnitudes of associations with lacunes and extensive WMHs (Figure 4). Specifically, in both studies of the general and high-risk-populations, we found gradually increasing associations estimates for concentric remodeling, eccentric hypertrophy, and concentric hypertrophy with the odds of lacunes and extensive WMHs.

Table 2 summarizes the results derived from eight studies (five in the general, three in high-risk populations) exploring associations between LVM or LVMI and heterogeneous methods for a continuous or ordinal assessment of WMHs severity or volume, which could not be included in the meta-analysis. In accordance with our main results, five of the eight studies showed statistically significant associations between higher LVM or LVMI and higher WMH severity or volume, while the association estimates were directionally consistent across all studies. 
Study (author, year)

OR $(95 \% \mathrm{Cl}) \quad \%$ Weight

General population

Das, 2008

Hirose, 2011

Johansen, 2018

Nakanishi, 2017

Tanizaki, 2000

Subtotal ( $\mid$-squared $=46.0 \%, P=0.116$ )

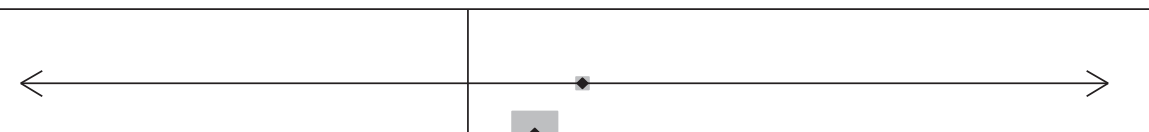

$1.51(0.17,13.04) \quad 1.74$

$1.27(0.78,2.06) \quad 20.39$

$1.08(0.78,1.51) \quad 29.30$

$2.14(1.35,3.41) \quad 21.48$

$1.80(1.25,2.59) \quad 27.09$

$1.49(1.12,2.00) \quad 100.00$

High risk population

Davis, 1998

Ikeda, 1994

Kawamoto, 1991

Kohara, 1999

Mounier-Vehier, 1993

Pirinen, 2017

Selvetella, 2003

Van der Veen, 2015

Subtotal (I-squared $=70.7 \%, P=0.001$ )

NOTE: Weights are from random effects analysis

$0.2 \quad 0.5$

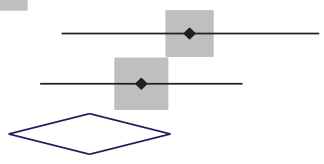

$1.77(0.85,3.71) \quad 14.45$

$2.29(1.17,4.51) \quad 14.99$

$23.33(4.27,127.57) \quad 7.38$

$3.76(1.81,7.79) \quad 14.51$

$1.22(0.37,4.09) \quad 10.56$

$1.66(0.69,4.03) \quad 13.18$

$5.89(2.50,13.90) \quad 13.39$

$0.47(0.16,1.38) \quad 11.54$

$2.39(1.32,4.32) \quad 100.00$

$0.2 \quad 0.5$

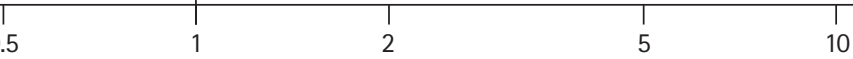

Study (author, year)

OR $(95 \% \mathrm{Cl}) \quad \%$ Weight

General population

Cermakova, 2017

Fox, 2005

Hirose, 2011

Jeerakathil, 2004

Nakanishi, 2017

Subtotal (I-squared $=0.0 \%, P=0.771)$

High risk population

Butenaerts, 2015

Ferreira, 2017

Henon, 1996

Henskens, 2009

Kohara, 1999

Martinez-Vea, 2006

Ryu, 2014

Shimada, 1990

Sierra, 2002

Van der Veen, 2015

Vedala, 2019

Subtotal (I-squared $=53.2 \%, P=0.019$ )

NOTE: Weights are from random effects analysis

$0.2 \quad 0.5$
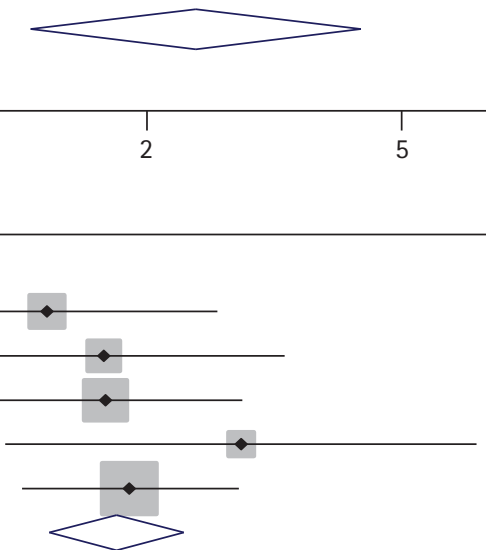

$1.81(1.26,2.62) \quad 38.50$

$1.73(1.38,2.17) \quad 100.00$

\begin{tabular}{c|c|}
\hline & 0.2
\end{tabular}

Figure 2. Associations of left ventricular hypertrophy with (A) lacunes, and (B) extensive white matter hyperintensities in general and high-risk population studies. Odds ratios (ORs) of each study are depicted as data markers; shaded boxes around the data markers indicate the statistical weight of the respective study; 95\% confidence intervals (Cls) are indicated by the error bars; pooled-effect estimates for general and high-risk populations along with their $95 \% \mathrm{Cl}$ are reflected as a diamond. 


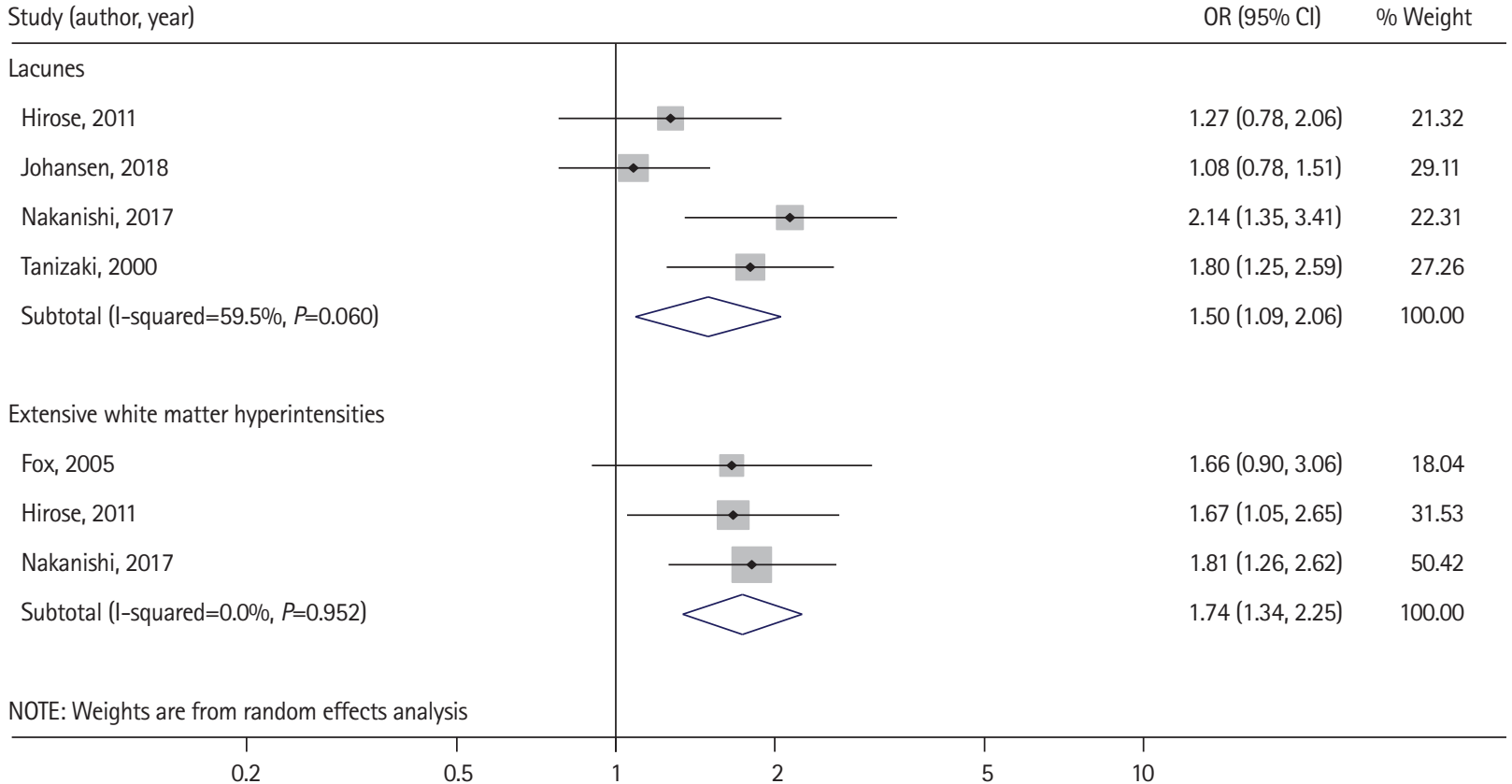

Figure 3. Associations of left ventricular hypertrophy with lacunes and extensive white matter hyperintensities in general population studies adjusting for age, sex, hypertension, and other vascular risk factors. Odds ratios (ORs) of each study are depicted as data markers; shaded boxes around the data markers indicate the statistical weight of the respective study; 95\% confidence intervals (Cls) are indicated by the error bars; pooled-effect estimates for general populations along with their $95 \% \mathrm{Cl}$ are reflected as a diamond.

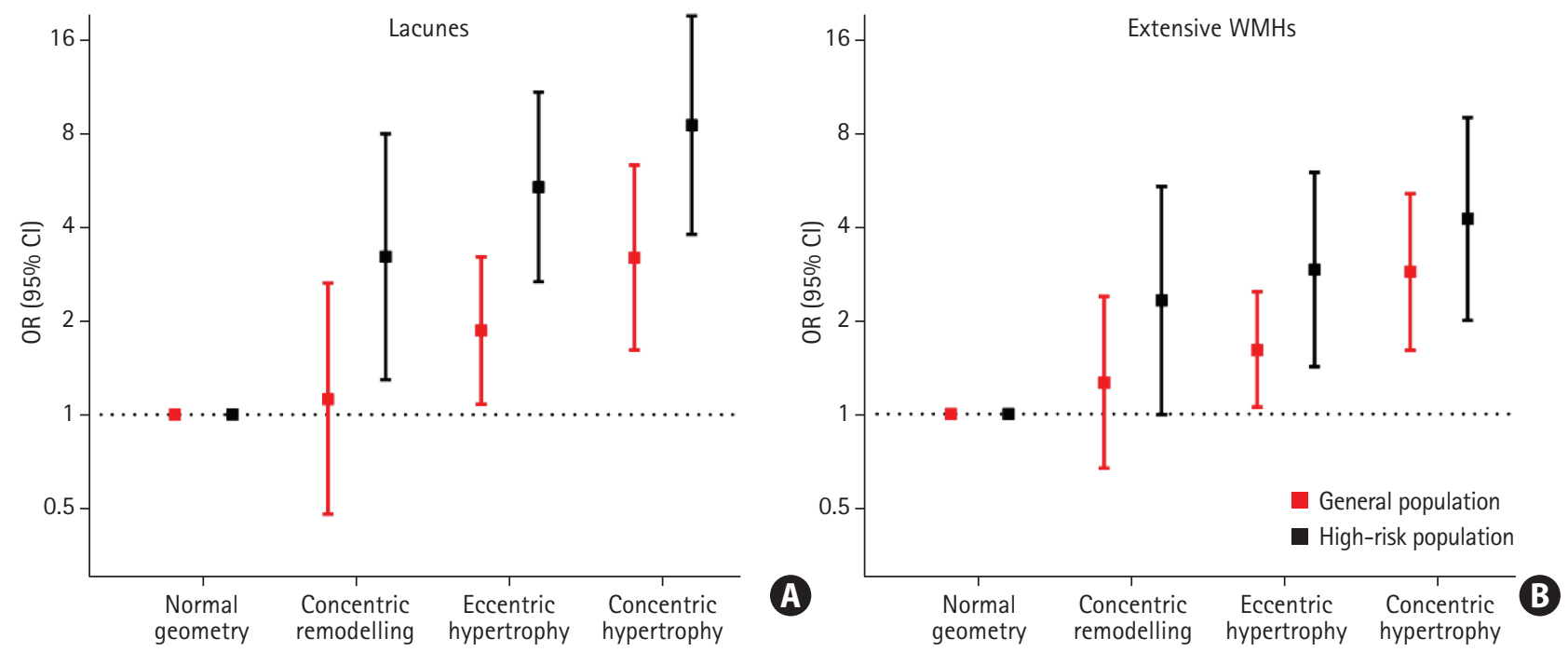

Figure 4. Associations of left ventricular morphology patterns (normal geometry, concentric remodeling, eccentric and concentric hypertrophy) with (A) lacunes and (B) extensive white matter hyperintensities (WMHs) in general (red lines) and high-risk (black lines) population studies. Odds ratios (ORs) are depicted as data markers and 95\% confidence intervals (Cls) are indicated by the error bars. All comparisons use "normal geometry" as the reference group (total number: lacunes general population, 665; lacunes high-risk population, 345; extensive WMHs general population, 665; extensive WMHs high-risk population, 419).

\section{Heterogeneity, subgroup and sensitivity analyses} In studies of the general population, meta-analyses of WMHs studies showed no heterogeneity $\left(I^{2}=0 \%, P=0.77\right)$, while those of lacunes only moderate heterogeneity $\left(I^{2}=46 \%, P=0.12\right)$ (Figure 2). In subgroup analyses the results were stable for both cross-sectional and cohort studies, as well as for studies assessing LVH by either ECG or TTE (Table 3). Additionally, when restricting our analyses to studies defining LVH with the currently considered most optimal approaches (ECG: only $\uparrow$ QRS voltage-based criteria; TTE: LVMI $\geq 95 \mathrm{~g} / \mathrm{m}^{2}$ for women and 
Table 2. Review of the results of studies examining the association between left ventricular mass or left ventricular mass index and white matter hyperintensity severity or volume that were not included in the meta-analysis

\begin{tabular}{|c|c|c|c|c|}
\hline Study & $\begin{array}{l}\text { Population } \\
\text { (total no.) }\end{array}$ & Association examined & Adjustments & Results \\
\hline $\begin{array}{l}\text { Cermakova et al. } \\
(2017)^{54}\end{array}$ & $\begin{array}{l}\text { General population } \\
\quad(n=627)\end{array}$ & $\begin{array}{l}\text { LVMI (per } 1 \mathrm{SD}, \mathrm{g} / \mathrm{m}^{2} \text { ) with the DTI } \\
\text { metric of white matter fractional } \\
\text { anisotropy* }\end{array}$ & $\begin{array}{l}\text { Age, sex, hypertension, diabetes, } \\
\text { smoking, alcohol, BMI, TC, } \\
\text { education, race, study site, } \\
\text { sedentary time, intracranial } \\
\text { volume, ApoE- } \varepsilon 4 \text { genotype }\end{array}$ & $\begin{array}{l}\text { Exposure standardized beta } \\
\text { coefficient } \beta=-0.001 \text { ( }-0.003 \text { to } \\
0.0003), P=0.11\end{array}$ \\
\hline Haring et al. $(2017)^{61}$ & $\begin{array}{l}\text { General population } \\
(\mathrm{n}=721)\end{array}$ & $\begin{array}{l}\text { LVM (per } 25 \mathrm{~g} \text { ) with (1) WMH } \\
\text { volume }(\%) \text {, normalized to total } \\
\text { intracranial volume; }(2) \text { graded } \\
\text { using a } 10 \text {-point scale }\end{array}$ & $\begin{array}{l}\text { Age, sex, hypertension, diabetes, } \\
\text { smoking, alcohol, BMI, aFib, } \\
\text { study site, education, income, } \\
\text { anxiety, ApoE- } \varepsilon 4 \text { genotype, fol- } \\
\text { low-up duration }\end{array}$ & $\begin{array}{l}\text { (1) Unstandardized beta coefficient } \\
\beta=0.019 \text { ( }-0.017 \text { to } 0.054), P=0.30 \text {, } \\
\text { (2) Unstandardized beta coefficient } \\
\beta=0.077 \text { ( }-0.001 \text { to } 0.155), P=0.05\end{array}$ \\
\hline $\begin{array}{l}\text { Johansen et al. } \\
\qquad(2018)^{21}\end{array}$ & $\begin{array}{l}\text { General population } \\
(n=1,665)\end{array}$ & $\begin{array}{l}\left.\text { LVMI (per } 10 \mathrm{~g} / \mathrm{m}^{2}\right) \text { with WMH } \\
\text { volume }\left(\mathrm{cm}^{3}\right) \text {, modelled by } \\
\text { generalized linear models with } \gamma \\
\text { families and identity links }\end{array}$ & $\begin{array}{l}\text { Age, sex, hypertension, diabetes, } \\
\text { smoking, alcohol, BMI, LDL-C, } \\
\text { MI, education, total intracranial } \\
\text { volume }\end{array}$ & $\begin{array}{l}\text { Unstandardized beta coefficient } \\
\beta=0.64(0.19 \text { to } 1.08)^{+}, P<0.01\end{array}$ \\
\hline Kohara et al. (1999) ${ }^{68}$ & $\begin{array}{l}\text { Hypertensive patients } \\
(n=150)\end{array}$ & $\begin{array}{l}\text { LVMI }\left(\mathrm{g} / \mathrm{m}^{2}\right) \text { with WMH grade } \\
\text { (scale } 1-4)\end{array}$ & $\begin{array}{l}\text { Age, hypertension, BMI, relative } \\
\text { wall thickness }\end{array}$ & $\begin{array}{l}\text { Partial correlation coefficient } r=0.33 \\
(0.195 \text { to } 0.465)^{\dagger}, P<0.01\end{array}$ \\
\hline Lee et al. $(2018)^{70}$ & $\begin{array}{l}\text { Valvular heart disease } \\
\text { patients }(n=217)\end{array}$ & $\begin{array}{l}\text { LVMI }\left(\mathrm{g} / \mathrm{m}^{2}\right) \text { with WMH volume } \\
(\mathrm{mL})\end{array}$ & Unadjusted & $\begin{array}{l}\text { Correlation coefficient } r=0.072 \\
(-0.061 \text { to } 0.205), P=0.29\end{array}$ \\
\hline Lee et al. $(2004)^{69}$ & $\begin{array}{r}\text { Hypertensive patients } \\
\text { with stroke }(n=102)\end{array}$ & $\begin{array}{l}\text { LVMI grade (scale 0-3) with WMH } \\
\text { grade (scale 0-3) }\end{array}$ & $\begin{array}{l}\text { Age, sex, hypertension, duration of } \\
\text { hypertension, diabetes, glucose, } \\
\text { smoking, BMI, total cholesterol, } \\
\text { haematocrit, creatinine, anti- } \\
\text { platelet use, prior stroke }\end{array}$ & $\begin{array}{l}\text { Ordinal logistic regression } \mathrm{OR}, 1.51 \\
(1.07 \text { to } 2.12)^{\dagger}, P<0.05\end{array}$ \\
\hline $\begin{array}{l}\text { Longstreth et al. } \\
(1996)^{71}\end{array}$ & $\begin{array}{l}\text { General population } \\
(n=3,301)\end{array}$ & $\begin{array}{l}\text { LVM (g) with WMH grade (scale } \\
1-8)\end{array}$ & Age, sex & $\begin{array}{l}\text { Partial correlation coefficient } r=0.067 \\
(0.021 \text { to } 0.113)^{\dagger}, P<0.01\end{array}$ \\
\hline Moore et al. (2018) ${ }^{20}$ & $\begin{array}{l}\text { General population } \\
(\mathrm{n}=313)\end{array}$ & $\begin{array}{l}\text { LVMI (per } 1 \mathrm{SD}, \mathrm{g} / \mathrm{m}^{2} \text { ) with DTI } \\
\text { metrics (per } 1 \mathrm{SD} \text { ) of white } \\
\text { matter microstructure (fractional } \\
\text { anisotropy*, mean, radial, axial } \\
\text { diffusivity) }\end{array}$ & $\begin{array}{l}\text { Age, sex, hypertension, anti-hyper- } \\
\text { tensive drug usage, diabetes, } \\
\text { smoking, CVD, aFib, education, } \\
\text { race/ethnicity, cognitive status, } \\
\text { ApoE- } \varepsilon 4 \text { genotype }\end{array}$ & $\begin{array}{l}\text { - Standardized beta coefficients pro- } \\
\text { vided, all } P \text {-values corrected for } \\
\text { multiple comparisons }<0.05^{+}\end{array}$ \\
\hline
\end{tabular}

LVMI, left ventricular mass index; SD, standard deviation; DTI, diffusion tensor imaging; BMI, body mass index; TC, total cholesterol; LVM, left ventricular hypertrophy; WMH, white matter hyperintensities; aFib, atrial fibrillation; ApoE, apolipoprotein $\mathrm{E}$; LDL-C, low density lipoprotein cholesterol; $\mathrm{MI}$, myocardial infarction; CVD, cardiovascular disease.

${ }^{*}$ Lower values of fractional anisotropy indicate loss of white matter integrity; ${ }^{+}$Results indicate statistical significance.

$\geq 115 \mathrm{~g} / \mathrm{m}^{2}$ for men, body surface indexed) the results remained stable (Table 3). Yet, we found moderate heterogeneity in studies of high-risk populations for both lacunes and WMHs $\left(I^{2}=71 \%, P=0.001\right.$ and $I^{2}=53 \%, P=0.02$, respectively) (Figure 2 ). Although none of the sub-analyses entirely resolved the heterogeneity, the results were stable across the examined subgroups (Table 3). Overall, sensitivity analyses restricted to studies fulfilling each one of the Newcastle-Ottawa criteria showed consistent associations of LVH with both lacunes and WMHs (Supplementary Table 6). In "leave-one-out" sensitivity metaanalyses, we found no evidence that any single study significantly influenced the results of the main analyses (Supplementary Figure 2).

\section{Assessment of publication bias}

Funnel plots for the main analyses are presented in the supple- ment (Supplementary Figure 3). We did not perform the Egger's test for meta-analyses of studies of the general population, or for high risk populations for the outcome lacunes due to $<10$ pooled studies. The Egger's test showed statistically significant small-study effects for the 11 high risk WMHs studies $(P=0.01)$. After adjusting this analysis for publication bias with the "trim and fill" method ${ }^{49}$ the association remained statistically significant (OR, 1.45; 95\% Cl, 1.03 to 2.04) (Supplementary Figure 4).

\section{Discussion}

Polling data from 31 studies and $>20,000$ individuals, we found $\mathrm{LVH}$ to be associated with neuroimaging markers of CSVD in both the general population and specific high-risk populations. Specifically, LVH, defined by TEE or ECG, and increased LVM, assessed by $T E$, were associated with lacunes, WMHs, and 
Table 3. Sensitivity and subgroup analyses for the associations between left ventricular hypertrophy and lacunes or extensive white matter hyperintensities in general and high-risk population studies stratified by study type, exposure and outcome assessment methods, and specific population subsets

\begin{tabular}{|c|c|c|c|c|c|c|c|c|c|c|}
\hline \multirow[b]{2}{*}{$\begin{array}{l}\text { Sensitivity and subgroup } \\
\text { analyses } \\
\text { LVH vs. no LVH }\end{array}$} & \multicolumn{5}{|c|}{ Lacunes } & \multicolumn{5}{|c|}{ WMHs } \\
\hline & $k^{*}$ & Total no. & OR (95\% Cl) & $\begin{array}{l}\text { Heterogene- } \\
\quad \text { ity, }{ }^{2}, P\end{array}$ & $\begin{array}{c}P \text { for } \\
\text { subgroup } \\
\text { difference }\end{array}$ & $k^{*}$ & Total no. & OR $(95 \% \mathrm{Cl})$ & $\begin{array}{l}\text { Heterogene- } \\
\text { ity, } I^{2}, P\end{array}$ & $\begin{array}{c}P \text { for } \\
\text { subgroup } \\
\text { difference }\end{array}$ \\
\hline \multicolumn{11}{|l|}{ General population } \\
\hline Overall analysis & 5 & 6,650 & $1.49(1.12-2.00)^{+}$ & $46 \%, 0.12$ & & 5 & 4,432 & $1.73(1.38-2.17)^{+}$ & $0 \%, 0.77$ & \\
\hline Study type & & & & & 0.12 & & & & & 0.77 \\
\hline Cross-sectional & 4 & 5,029 & $1.40(0.97-2.01)$ & $47 \%, 0.13$ & & 4 & 3,805 & $1.81(1.41-2.32)^{+}$ & $0 \%, 0.79$ & \\
\hline Cohort & 1 & 1,621 & $1.80(1.25-2.59)^{+}$ & NA & & 1 & 627 & $1.37(0.77-2.44)$ & - & \\
\hline Exposure assessment & & & & & $0.12^{+}$ & & & & & $0.77^{+}$ \\
\hline ECG & 3 & 4,320 & $1.59(1.19-2.12)^{+}$ & $0 \%, 0.53$ & & 2 & 2,473 & $1.87(1.26-2.80)^{+}$ & $0 \%, 0.33$ & \\
\hline $\begin{array}{l}\text { Only } \uparrow Q R S \text { voltage-based } \\
\text { criteria }\end{array}$ & 2 & 2,280 & $1.57(1.13-2.19)^{+}$ & $21 \%, 0.26$ & $0.06^{\varsigma}$ & 1 & 659 & $1.67(1.05-2.65)^{+}$ & - & $0.73^{\S}$ \\
\hline TTE & 2 & 2,330 & $1.49(0.76-2.91)$ & $82 \%, 0.02$ & & 3 & 1,959 & $1.67(1.27-2.20)^{+}$ & $0 \%, 0.73$ & \\
\hline $\begin{array}{l}\text { LVMI } \geq 95 \mathrm{~g} / \mathrm{m}^{2}(\mathrm{~F}), \geq 115 \\
\mathrm{~g} / \mathrm{m}^{2}(\mathrm{M})\end{array}$ & 2 & 2,330 & $1.49(0.76-2.91)$ & $82 \%, 0.02$ & & 2 & 1,292 & $1.67(1.23-2.28)^{+}$ & $0 \%, 0.42$ & \\
\hline Outcome assessment & & & & & - & & & & & - \\
\hline CT & 0 & - & - & - & & 0 & - & - & - & \\
\hline MRI & 4 & 5,029 & $1.40(0.97-2.01)$ & $47 \%, 0.13$ & & 5 & 4,432 & $1.73(1.38-2.17)^{+}$ & $0 \%, 0.77$ & \\
\hline \multicolumn{11}{|l|}{ High-risk populations } \\
\hline Overall analysis & 8 & 6,879 & $2.39(1.32-4.32)^{+}$ & $71 \%, 0.00$ & & 11 & 4,867 & $2.01(1.45-2.80)^{+}$ & $53 \%, 0.02$ & \\
\hline Study type & & & & & 0.00 & & & & & 0.02 \\
\hline Cross-sectional & 6 & 1,480 & $3.20(1.75-5.87)^{+}$ & $61 \%, 0.02$ & & 10 & 4,222 & $1.74(1.36-2.22)^{+}$ & $12 \%, 0.34$ & \\
\hline Cohort & 2 & 5,399 & $0.97(0.27-3.53)$ & $75 \%, 0.05$ & & 2 & 776 & $2.90(0.42-19.84)$ & $92 \%, 0.00$ & \\
\hline Exposure assessment & & & & & $0.00^{+}$ & & & & & $0.06^{+}$ \\
\hline ECG & 6 & 6,534 & $1.73(0.85-3.55)$ & $71 \%, 0.00$ & & 4 & 1,420 & $2.41(0.98-5.90)$ & $78 \%, 0.00$ & \\
\hline $\begin{array}{l}\text { Only } \uparrow Q R S \text { voltage-based } \\
\text { criteria }\end{array}$ & 2 & 900 & $0.92(0.27-3.16)$ & $68 \%, 0.08$ & - & 2 & 776 & $2.90(0.42-19.84)$ & $92 \%, 0.00$ & $0.00^{\S}$ \\
\hline TTE & 3 & 940 & $3.33(1.53-7.24)^{+}$ & $54 \%, 0.11$ & & 6 & 778 & $2.31(1.57-3.39)^{+}$ & $0 \%, 0.91$ & \\
\hline $\begin{array}{l}\text { LVMI } \geq 95 \mathrm{~g} / \mathrm{m}^{2}(\mathrm{~F}), \geq 115 \\
\mathrm{~g} / \mathrm{m}^{2}(\mathrm{M})\end{array}$ & 0 & - & - & - & & 2 & 347 & $1.84(1.02-3.31)^{+}$ & $0 \%, 0.51$ & \\
\hline Outcome assessment & & & & & 0.00 & & & & & 0.02 \\
\hline CT & 2 & 844 & $1.97(1.09-3.55)^{+}$ & $0 \%, 0.37$ & & 1 & 610 & $1.54(0.71-3.33)$ & NA & \\
\hline MRI & 4 & 1,062 & $3.62(1.00-13.14)^{+}$ & $85 \%, 0.00$ & & 10 & 4,257 & $2.11(1.47-3.04)^{+}$ & $58 \%, 0.01$ & \\
\hline $\begin{array}{l}\text { Specific high-risk population } \\
\text { subsets }\end{array}$ & & & & & 0.02 & & & & & 0.02 \\
\hline Hypertensive patients & 5 & 5,384 & $3.67(1.97-6.86)^{+}$ & $63 \%, 0.03$ & & 5 & 551 & $3.18(1.70-5.97)^{+}$ & $41 \%, 0.15$ & \\
\hline Stroke patients & 1 & 595 & $1.22(0.37-4.09)$ & NA & & 4 & 3,601 & $1.57(1.17-2.11)^{+}$ & $21 \%, 0.28$ & \\
\hline
\end{tabular}

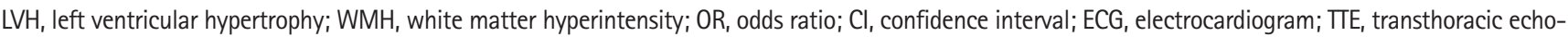

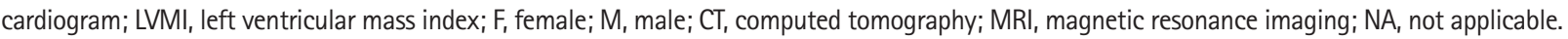

*Numbers of studies in each category do not always add up to the total for a number of different reasons, e.g., article presents additional analyses, article does

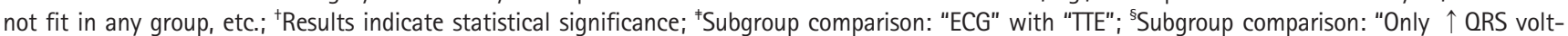
age-based criteria" (i.e., Sokolow-Lyon/ Cornell/ Minessota code 3-1) with "LVMI $\geq 95 \mathrm{~g} / \mathrm{m}^{2}$ (female), $\geq 115 \mathrm{~g} / \mathrm{m}^{2}$ (male)".

CMBs. Both eccentric and concentric LVH were associated with CSVD manifestations, but the latter presented larger association estimates. The results remained stable after adjustments for age, hypertension, and other vascular risk factors, in both cross-sectional and cohort studies, as well as in sensitivity analyses controlling for study quality. Among studies of the general population, there was no evidence of heterogeneity for studies assessing WMHs and only moderate heterogeneity for 
studies assessing lacunes.

Our results demonstrate an association of LVH with lacunes, WMHs, and CMBs, independently of age, hypertension, and other vascular risk factors. This is in accordance with studies exploring other vascular beds and endpoints. Particularly, both electrocardiographic and echocardiographic LVH has been previously associated with the risk of incident adverse coronary events, ${ }^{14}$ ischemic stroke, ${ }^{16-18}$ and all-cause mortality ${ }^{14,81}$ in studies of the general population. Similar to our results, these associations appear to be independent of hypertension, and taken all together, suggest that $\mathrm{LVH}$ is an independent risk factor for global vascular disease.

However, the underlying hemodynamic mechanisms remain largely elusive. During the course of LVH there is initially preserved systolic function and only mild diastolic dysfunction, ${ }^{13}$ but over time both systolic and diastolic dysfunction ensue. ${ }^{82}$ The decrease in stroke volume with its accompanying systemic hypoperfusion could predispose to cerebral ischemia and CSVD. ${ }^{83,84}$ Additionally, the concomitant increased fibroblastic activity in the cardiac extracellular matrix can induce arrhythmias, $_{1}^{13}$ which may cause hypotensive episodes, cerebral hypoperfusion, and CSVD. ${ }^{85}$ Yet, it remains unknown if LVH could also influence the risk of CSVD during its earlier stages, when no systolic or diastolic dysfunction has developed.

Apart from LVM itself, when further exploring different LV geometry patterns, we documented that concentric hypertrophy showed the strongest association with lacunes and WMHs. In patients with hypertension and abnormal LV geometry, concentric patterns appear to be more common than eccentric, due to pressure but not volume overload. ${ }^{13}$ Concentric hypertrophy has been associated with the highest risk of both ischemic stroke, ${ }_{1}^{86}$ as well as cardiovascular and all-cause mortali$\mathrm{ty}_{1}{ }^{81}$ when compared to other abnormal LV geometry patterns. A possible explanation for this could be related to the fact that concentric hypertrophy, in comparison to eccentric, is generally associated with higher LVM, as was also observed in some of the included studies in the current review. ${ }^{22,68}$ Furthermore, specific LV geometry patterns reflect not only differences in hemodynamic load but also genetic predisposition. ${ }^{87,88}$ It is therefore plausible that our observations could result from a common genetic predisposition to both cerebral microvascular disease and cardiac maladaptive remodelling in response to hemodynamic load. Regardless of the potential mechanism(s), our results highlight the need for further exploration of LV geometry patterns in future CSVD studies.

Our study finding for an association between LVH and CSVD could explain previous observations regarding the effects of LVH on other endpoints. ${ }^{18,19}$ Specifically, in a previous meta- analysis, we found LVH to be strongly associated with cognitive impairment and decline, ${ }^{19}$ whereas more recent longitudinal studies have shown LVH to be associated with the risk of incident dementia independently of known vascular risk factors. ${ }^{89,90}$ Furthermore, multiple studies have shown that LVH is an independent risk factor for stroke. ${ }^{16-18}$ With CSVD being a well-established cause of vascular cognitive impairment, ischemic and hemorrhagic stroke, our findings implicate LVH as a potential mediator in these associations. Future longitudinal studies utilizing serial assessments of LVH, CSVD, cognitive, and vascular endpoints should formally explore this hypothesis.

According to current guidelines, patients with hypertension may undergo brain imaging for assessment of hypertension-mediated organ damage only if neurological symptoms or cognitive decline are present. ${ }^{91}$ Future large studies should explore the potential benefit of performing brain imaging for all hypertensive patients diagnosed with LVH. Notably, it has been demonstrated that LVH regression via antihypertensive medications leads to risk reduction for future major cardiovascular events. ${ }^{92,93}$ On the basis of our findings, future randomized-controlled clinical trials exploring pharmacological LVH regression should include CSVD neuroimaging assessment as a secondary outcome.

Despite the consistency of our findings when controlling for hypertension, our results could still be explained by residual confounding due to insufficient adjustments for high blood pressure duration in the individual studies. Hypertension is the primary risk factor for both $\mathrm{LVH}^{13}$ and $\mathrm{CSVD}_{1}{ }^{1,2,94}$ increasing the risk in a time-dependent manner. In our study set, the cross-sectional design of the majority of the included studies precluded serial blood pressure measurements. Although some studies variably adjusted for hypertension duration, ${ }^{58,69}$ this also does not entirely capture its actual duration, as a highly variable subclinical period of high blood pressure often precedes the clinical diagnosis. Future studies should address this critical issue.

Our study also has limitations. First, the studies used highly heterogeneous ECG and TTE-based LVH definitions, and assessed CSVD markers, especially WMHs, with variable approaches. Yet, only moderate heterogeneity was identified in studies of the general population and the results remained stable across sub-analyses grouped by different methods of LVH or CSVD assessment. Second, the risk of bias assessment identified key methodological limitations among the included studies. These limitations were mainly related to the cross-sectional design the majority of the included studies employed and to inadequate adjustments for major confounding factors. For several of the included studies it was only possible to use unadjusted or minorly adjusted effect estimates in the metaanalysis, which are biased by confounding. Yet, sensitivity 
analyses, where possible, demonstrated consistency of our results among cohort studies and studies controlling for age, hypertension and other vascular risk factors. Third, the heterogeneous statistical methods applied across studies did not allow us to include all studies in the meta-analysis. However, the individual findings from these studies consistently support our pooled results. Fourth, no study utilized a composite CSVD score, which could add information regarding the entire spectrum of CSVD manifestations. Fifth, the lack of prospective studies did not allow us to dynamically explore the association between LVH progression and neuroimaging markers of CSVD.

\section{Conclusions}

Our results support an association of echocardiographically or electrocardiographically-defined LVH and echocardiographically-assessed LVM increase with a broad range of CSVD neuroimaging markers, including lacunes, WMHs and CMBs, independently of hypertension and other vascular risk factors. As such, our findings highlight a link between subclinical heart disease and CSVD and indicate LVH as a potential novel risk factor for CSVD and its clinical sequelae.

\section{Supplementary materials}

Supplementary materials related to this article can be found online at https://doi.org/10.5853/jos.2019.03335.

\section{Disclosure}

The authors have no financial conflicts of interest.

\section{Acknowledgments}

We are grateful to Dr. Takuo Hirose (Sendai, Japan) and Dr. Marco R. Di Tullio (New York, USA) for taking the time to reply to our request for supplementary analyses based on their published data.

\section{References}

1. Pantoni L. Cerebral small vessel disease: from pathogenesis and clinical characteristics to therapeutic challenges. Lancet Neurol 2010;9:689-701.

2. Wardlaw JM, Smith $C$, Dichgans M. Small vessel disease: mechanisms and clinical implications. Lancet Neurol 2019;18:684-696.

3. Dichgans M, Leys D. Vascular cognitive impairment. Circ Res
2017; 120:573-591.

4. Sudlow CL, Warlow CP. Comparable studies of the incidence of stroke and its pathological types: results from an international collaboration. International Stroke Incidence Collaboration. Stroke 1997;28:491-499.

5. Qureshi Al, Tuhrim S, Broderick JP, Batjer HH, Hondo H, Hanley DF. Spontaneous intracerebral hemorrhage. N Engl J Med 2001;344:1450-1460.

6. Debette $\mathrm{S}$, Schilling S, Duperron MG, Larsson SC, Markus HS. Clinical significance of magnetic resonance imaging markers of vascular brain injury: a systematic review and meta-analysis. JAMA Neuro/ 2019;76:81-94.

7. Georgakis MK, Duering M, Wardlaw JM, Dichgans M. WMH and long-term outcomes in ischemic stroke: a systematic review and meta-analysis. Neurology 2019;92:e1298-e1308.

8. de Laat KF, van Norden AG, Gons RA, van Oudheusden $\sqcup$, van Uden IW, Bloem BR, et al. Gait in elderly with cerebral small vessel disease. Stroke 2010;41:1652-1658.

9. Inzitari D, Pracucci G, Poggesi A, Carlucci G, Barkhof F, Chab-

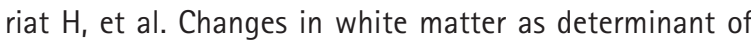
global functional decline in older independent outpatients: three year follow-up of LADIS (leukoaraiosis and disability) study cohort. BMJ 2009;339:b2477.

10. van Agtmaal MJM, Houben AJHM, Pouwer F, Stehouwer CDA, Schram MT. Association of microvascular dysfunction with late-life depression: a systematic review and metaanalysis. JAMA Psychiatry 2017;74:729-739.

11. Wardlaw JM, Smith EE, Biessels GJ, Cordonnier C, Fazekas F, Frayne $R$, et al. Neuroimaging standards for research into small vessel disease and its contribution to ageing and neurodegeneration. Lancet Neurol 2013;12:822-838.

12. de Leeuw FE, de Groot JC, Achten E, Oudkerk M, Ramos LM, Heijboer $R$, et al. Prevalence of cerebral white matter lesions in elderly people: a population based magnetic resonance imaging study. The Rotterdam Scan Study. J Neurol Neurosurg Psychiatry 2001;70:9-14.

13. Marwick TH, Gillebert TC, Aurigemma G, Chirinos J, Derumeaux $\mathrm{G}$, Galderisi $\mathrm{M}$, et al. Recommendations on the use of echocardiography in adult hypertension: a report from the European Association of Cardiovascular Imaging (EACVI) and the American Society of Echocardiography (ASE). Eur Heart J Cardiovasc Imaging 2015;16:577-605.

14. Levy D, Garrison RJ, Savage DD, Kannel WB, Castelli WP. Prognostic implications of echocardiographically determined left ventricular mass in the Framingham Heart Study. N Engl J Med 1990;322:1561-1566.

15. Wolf PA, D'Agostino RB, Belanger AJ, Kannel WB. Probability of stroke: a risk profile from the Framingham Study. Stroke 
1991;22:312-318.

16. Bikkina M, Levy D, Evans JC, Larson MG, Benjamin EJ, Wolf $\mathrm{PA}$, et al. Left ventricular mass and risk of stroke in an elderly cohort. The Framingham Heart Study. JAMA 1994;272:3336.

17. O'Neal WT, Almahmoud MF, Qureshi WT, Soliman EZ. Electrocardiographic and Echocardiographic left ventricular hypertrophy in the prediction of stroke in the elderly. J Stroke Cerebrovasc Dis 2015;24:1991-1997.

18. Bots ML, Nikitin Y, Salonen JT, Elwood PC, Malyutina S, Freire de Concalves $A$, et al. Left ventricular hypertrophy and risk of fatal and non-fatal stroke. EUROSTROKE: a collaborative study among research centres in Europe. J Epidemiol Community Health 2002;56 Suppl 1:i8-i13.

19. Georgakis MK, Synetos A, Mihas C, Karalexi MA, Tousoulis D, Seshadri $S$, et al. Left ventricular hypertrophy in association with cognitive impairment: a systematic review and metaanalysis. Hypertens Res 2017;40:696-709.

20. Moore EE, Liu D, Pechman KR, Terry JG, Nair S, Cambronero $\mathrm{FE}_{\text {, et }}$ al. Increased left ventricular mass index is associated with compromised white matter microstructure among older adults. J Am Heart Assoc 2018;7:e009041.

21. Johansen MC, Shah AM, Lirette ST, Griswold M, Mosley $T_{1}$ Solomon SD, et al. Associations of echocardiography markers and vascular brain lesions: the ARIC Study. J Am Heart Assoc 2018;7:e008992.

22. Nakanishi $K$, Jin Z, Homma S, Elkind MS, Rundek T, Tugcu A, et al. Left ventricular mass-geometry and silent cerebrovascular disease: the cardiovascular abnormalities and brain lesions (CABL) study. Am Heart J 2017;185:85-92.

23. Stroup DF, Berlin JA, Morton SC, Olkin I, Williamson GD, Rennie $D$, et al. Meta-analysis of observational studies in epidemiology: a proposal for reporting. Meta-analysis Of Observational Studies in Epidemiology (MOOSE) group. JAMA 2000;283:2008-2012.

24. Soliman EZ, Howard G, Prineas RJ, McClure LA, Howard VJ. Calculating Cornell voltage from nonstandard chest electrode recording site in the Reasons for Geographic And Racial Differences in Stroke study. J Electrocardiol 2010;43:209-214.

25. Gosse $P_{1}$ Jan $E_{1}$ Coulon $P_{1}$ Cremer $A$, Papaioannou G, Yeim S. ECG detection of left ventricular hypertrophy: the simpler, the better? J Hypertens 2012;30:990-996.

26. Devereux RB, Alonso DR, Lutas EM, Gottlieb GJ, Campo $E_{1}$ Sachs I, et al. Echocardiographic assessment of left ventricular hypertrophy: comparison to necropsy findings. Am J Cardiol 1986;57:450-458.

27. Ferguson KJ, Cvoro V, MacLullich AMJ, Shenkin SD, Sandercock PAG, Sakka $E_{1}$ et al. Visual rating scales of white matter hyperintensities and atrophy: comparison of computed tomography and magnetic resonance imaging. J Stroke Cerebrovasc Dis 2018;27:1815-1821.

28. Simoni M, Li L, Paul NL, Gruter BE, Schulz UG, Küker W, et al. Age- and sex-specific rates of leukoaraiosis in TIA and stroke patients: population-based study. Neurology 2012;79:12151222.

29. Wells G, Shea B, O'Connell D, Peterson J, Welch V, Losos M, et al. The Newcastle-Ottawa Scale (NOS) for assessing the quality if nonrandomized studies in meta-analyses. Ottawa Hospital Research Institute. http://www.ohri.ca/programs/ clinical_epidemiology/oxford.Asp. 2011. Accessed March 26, 2020.

30. McNutt LA, Wu $C$, Xue $X$, Hafner JP. Estimating the relative risk in cohort studies and clinical trials of common outcomes. Am J Epidemiol 2003;157:940-943.

31. Hamling J, Lee $P$, Weitkunat $R$, Ambühl M. Facilitating metaanalyses by deriving relative effect and precision estimates for alternative comparisons from a set of estimates presented by exposure level or disease category. Stat Med 2008;27:954970.

32. Polanin JR, Snilstveit B. Converting between effect sizes. Campbell Syst Rev 2016;12:1-13.

33. DerSimonian R, Laird N. Meta-analysis in clinical trials. Control Clin Trials 1986;7:177-188.

34. Paule RC, Mandel J. Consensus values, regressions, and weighting factors. J Res Natl Inst Stand Technol 1989;94:197203.

35. Hartung J, Knapp G. On tests of the overall treatment effect in meta-analysis with normally distributed responses. Stat Med 2001;20:1771-1782.

36. Knapp G, Hartung J. Improved tests for a random effects meta-regression with a single covariate. Stat Med 2003;22:26932710.

37. Sterne JAC. Meta-Analysis in Stata: An Updated Collection from the Stata Journal. 1st ed. College Station, TX: Stata Press, 2009.

38. Cornell JE, Mulrow CD, Localio R, Stack CB, Meibohm AR, Guallar $E_{1}$ et al. Random-effects meta-analysis of inconsistent effects: a time for change. Ann Intern Med 2014;160:267-270.

39. Sidik K, Jonkman JN. A note on the empirical Bayes heterogeneity variance estimator in meta-analysis. Stat Med 2019;38:3804-3816.

40. Veroniki AA, Jackson D, Viechtbauer W, Bender R, Bowden J, Knapp G, et al. Methods to estimate the between-study variance and its uncertainty in meta-analysis. Res Synth Methods 2016;7:55-79.

41. Röver C, Knapp G, Friede T. Hartung-Knapp-Sidik-Jonkman ap- 
proach and its modification for random-effects meta-analysis with few studies. BMCMed Res Methodo/ 2015;15:99.

42. IntHout J, loannidis JP, Borm GF. The Hartung-Knapp-SidikJonkman method for random effects meta-analysis is straightforward and considerably outperforms the standard DerSimonian-Laird method. BMC Med Res Methodol 2014;14:25.

43. Jackson D, Law M, Rücker G, Schwarzer G. The HartungKnapp modification for random-effects meta-analysis: a useful refinement but are there any residual concerns? Version 2. Stat Med 2017;36:3923-3934.

44. Zeraatkar D, Han M, Ge L, Hanna SE, Guyatt GH. A comparison of the Hartung-Knapp-Sidik-Jonkman method for metaanalysis with conventional frequentist methods: a systematic review of simulation and empirical studies. Cochrane Colloquium Santiago. https://colloquium2019.cochrane.org/abstracts/comparison-hartung-knapp-sidik-jonkman-methodmeta-analysis-conventional-frequentist. 2019. Accessed May 13, 2020.

45. van Aert RCM, Jackson D. A new justification of the Hartung-Knapp method for random-effects meta-analysis based on weighted least squares regression. Res Synth Methods 2019;10:515-527.

46. Jackson D, Bowden J, Baker R. How does the DerSimonian and Laird procedure for random effects meta-analysis compare with its more efficient but harder to compute counterparts? J Stat Plan Inference 2010;140:961-970.

47. Higgins JP, Thompson SG, Deeks JJ, Altman DG. Measuring inconsistency in meta-analyses. BMJ 2003;327:557-560.

48. Egger M, Davey Smith G, Schneider M, Minder C. Bias in metaanalysis detected by a simple, graphical test. BMJ 1997;315: 629-634.

49. Duval S, Tweedie R. Trim and fill: A simple funnel-plot-based method of testing and adjusting for publication bias in meta-analysis. Biometrics 2000;56:455-463.

50. Bezerra DC, Sharrett AR, Matsushita K, Gottesman RF, Shibata $D$, Mosley TH Jr, et al. Risk factors for lacune subtypes in the Atherosclerosis Risk in Communities (ARIC) Study. Neurology 2012;78:102-108.

51. Kohara $K$, Igase $M$, Yinong J, Fukuoka $T$, Maguchi M, Okura $T$, et al. Asymptomatic cerebrovascular damages in essential hypertension in the elderly. Am J Hypertens 1997;10:829-835.

52. Ohira T, Shahar E, Chambless LE, Rosamond WD, Mosley TH Jr, Folsom AR. Risk factors for ischemic stroke subtypes: the Atherosclerosis Risk in Communities study. Stroke 2006;37:24932498.

53. Butenaerts D, Chrzanowska-Wasko J, Slowik A, Dziedzic T. Left ventricular geometry and white matter lesions in isch- emic stroke patients. Blood Press 2016;25:149-154.

54. Cermakova P, Muller M, Armstrong AC, Religa D, Bryan RN, Lima JAC, et al. Subclinical cardiac dysfunction and brain health in midlife: CARDIA (Coronary Artery Risk Development in Young Adults) brain magnetic resonance imaging substudy. J Am Heart Assoc 2017;6:e006750.

55. Vedala K, Nagabandi AK, Looney S, Bruno A. Factors associated with leukoaraiosis severity in acute stroke patients. J Stroke Cerebrovasc Dis 2019;28:1897-1901.

56. Das RR, Seshadri S, Beiser AS, Kelly-Hayes M, Au R, Himali JJ, et al. Prevalence and correlates of silent cerebral infarcts in the Framingham offspring study. Stroke 2008;39:2929-2935.

57. Davis BR, Vogt T, Frost PH, Burlando A, Cohen J, Wilson A, et al. Risk factors for stroke and type of stroke in persons with isolated systolic hypertension. Systolic Hypertension in the Elderly Program Cooperative Research Group. Stroke 1998;29: 1333-1340.

58. Ferreira JP, Kearney Schwartz A, Watfa G, Zohra L, Felblinger J, Boivin JM, et al. Memory alterations and white matter hyperintensities in elderly patients with hypertension: the ADELAHYDE-2 study. J Am Med Dir Assoc 2017;18:451.

59. Fox ER, Taylor HA Jr, Benjamin EJ, Ding J, Liebson PR, Arnett $D$, et al. Left ventricular mass indexed to height and prevalent MRI cerebrovascular disease in an African American cohort: the Atherosclerotic Risk in Communities study. Stroke 2005;36:546-550.

60. Görner $A$, Lemmens $R$, Schrooten $M$, Thijs $V$. is leukoaraiosis on $\mathrm{CT}$ an accurate surrogate marker for the presence of microbleeds in acute stroke patients? J Neurol 2007;254:284289.

61. Haring B, Omidpanah A, Suchy-Dicey AM, Best LG, Verney $S P$, Shibata DK, et al. Left ventricular mass, brain magnetic resonance imaging, and cognitive performance: results from the strong heart study. Hypertension 2017;70:964-971.

62. Hénon $H$, Godefroy $\mathrm{O}$, Lucas $\mathrm{C}$, Pruvo JP, Leys D. Risk factors and leukoaraiosis in stroke patients. Acta Neurol Scand 1996;94:137-144.

63. Henskens LH, van Oostenbrugge RJ, Kroon AA, Hofman PA, Lodder J, de Leeuw PW. Detection of silent cerebrovascular disease refines risk stratification of hypertensive patients. $J$ Hypertens 2009;27:846-853.

64. Hirose T, Hashimoto M, Totsune K, Metoki H, Hara A, Satoh $M$, et al. Association of (pro)renin receptor gene polymorphisms with lacunar infarction and left ventricular hypertrophy in Japanese women: the Ohasama study. Hypertens Res 2011;34:530-535.

65. Ikeda T, Gomi T, Kobayashi S, Tsuchiya H. Role of hypertension in asymptomatic cerebral lacunae in the elderly. Hyper- 
tension 1994;23:I259-I262.

66. Jeerakathil T, Wolf PA, Beiser A, Massaro J, Seshadri S, D'Agostino RB, et al. Stroke risk profile predicts white matter hyperintensity volume: the Framingham Study. Stroke 2004;35: 1857-1861.

67. Kawamoto A, Shimada K, Matsubayashi K, Nishinaga $M$, Kimura S, Ozawa T. Factors associated with silent multiple lacunar lesions on magnetic resonance imaging in asymptomatic elderly hypertensive patients. Clin Exp Pharmacol Physiol 1991;18:605-610.

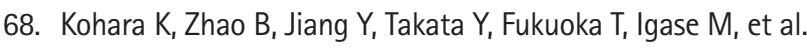
Relation of left ventricular hypertrophy and geometry to asymptomatic cerebrovascular damage in essential hypertension. Am J Cardiol 1999;83:367-370.

69. Lee SH, Park JM, Kwon SJ, Kim H, Kim YH, Roh JK, et al. Left ventricular hypertrophy is associated with cerebral microbleeds in hypertensive patients. Neurology 2004;63:16-21.

70. Lee WJ, Jung KH, Ryu YJ, Kim JM, Lee ST, Chu K, et al. Association of cardiac hemodynamic factors with severity of white matter hyperintensities in chronic valvular heart disease. JAMA Neurol 2018;75:80-87.

71. Longstreth WT Jr, Manolio TA, Arnold A, Burke GL, Bryan N, Jungreis $C A$, et al. Clinical correlates of white matter findings on cranial magnetic resonance imaging of 3301 elderly people. The Cardiovascular Health Study. Stroke 1996;27:12741282.

72. Martinez-Vea A, Salvadó $E_{1}$ Bardaji $A$, Gutierrez $C$, Ramos $A$, Garcia $C$, et al. Silent cerebral white matter lesions and their relationship with vascular risk factors in middle-aged predialysis patients with CKD. Am J Kidney Dis 2006;47:241-250.

73. Mounier-Vehier F, Leys D, Rondepierre P, Godefroy O, Pruvo $J P$. Silent infarcts in patients with ischemic stroke are related to age and size of the left atrium. Stroke 1993;24:13471351.

74. Pirinen J, Eranti $A$, Knekt $P$, Lehto $M$, Martinez-Majander $N$, Aro $A L$, et al. ECG markers associated with ischemic stroke at young age: a case-control study. Ann Med 2017;49:562-568.

75. Ryu WS, Woo SH, Schellingerhout D, Chung MK, Kim CK, Jang $\mathrm{MU}$, et al. Grading and interpretation of white matter hyperintensities using statistical maps. Stroke 2014;45:3567-3575.

76. Selvetella G, Notte A, Maffei A, Calistri V, Scamardella V, Frati $G$, et al. Left ventricular hypertrophy is associated with asymptomatic cerebral damage in hypertensive patients. Stroke 2003;34:1766-1770.

77. Shimada K, Kawamoto A, Matsubayashi K, Ozawa T. Silent cerebrovascular disease in the elderly: correlation with ambulatory pressure. Hypertension 1990;16:692-699.

78. Sierra $C$, de la Sierra $A$, Paré JC, Gómez-Angelats $E_{1}$ Coca $A$.
Correlation between silent cerebral white matter lesions and left ventricular mass and geometry in essential hypertension. Am J Hypertens 2002;15:507-512.

79. Tanizaki Y, Kiyohara Y, Kato I, Iwamoto H, Nakayama K, Shinohara $\mathrm{N}$, et al. Incidence and risk factors for subtypes of cerebral infarction in a general population: the Hisayama study. Stroke 2000;31:2616-2622.

80. van der Veen PH, Geerlings MI, Visseren FL, Nathoe HM, Mali WP, van der Graaf $Y$, et al. Hypertensive target organ damage and longitudinal changes in brain structure and function: the second manifestations of arterial disease-magnetic resonance study. Hypertension 2015;66:1152-1158.

81. Ghali JK, Liao Y, Cooper RS. Influence of left ventricular geometric patterns on prognosis in patients with or without coronary artery disease. J Am Coll Cardiol 1998;31:1635-1640.

82. Palmieri V, Wachtell K, Gerdts E, Bella JN, Papademetriou V,

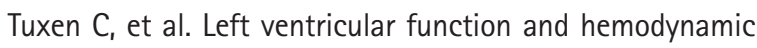
features of inappropriate left ventricular hypertrophy in patients with systemic hypertension: the LIFE study. Am Heart J 2001;141:784-791.

83. Shimizu A, Sakurai T, Mitsui T, Miyagi M, Nomoto $K$, Kokubo $M$, et al. Left ventricular diastolic dysfunction is associated with cerebral white matter lesions (leukoaraiosis) in elderly patients without ischemic heart disease and stroke. Geriatr Gerontol Int 2014;14 Suppl 2:71-76.

84. Vogels RL, van der Flier WM, van Harten $B$, Gouw AA, Scheltens $P$, Schroeder-Tanka JM, et al. Brain magnetic resonance imaging abnormalities in patients with heart failure. Eur J Heart Fail 2007;9:1003-1009.

85. Mok V, Kim JS. Prevention and management of cerebral small vessel disease. J Stroke 2015;17:111-122.

86. Di Tullio MR, Zwas DR, Sacco RL, Sciacca RR, Homma S. Left ventricular mass and geometry and the risk of ischemic stroke. Stroke 2003;34:2380-2384.

87. Arnett DK, Hong Y, Bella JN, Oberman A, Kitzman DW, Hopkins $\mathrm{PN}$, et al. Sibling correlation of left ventricular mass and geometry in hypertensive African Americans and whites: the HyperGEN study. Hypertension Genetic Epidemiology Network. Am J Hypertens 2001;14:1226-1230.

88. Schunkert H, Bröckel U, Hengstenberg C, Luchner A, Muscholl MW, Kurzidim K, et al. Familial predisposition of left ventricular hypertrophy. J Am Coll Cardiol 1999;33:16851691.

89. Norby FL, Chen LY, Soliman EZ, Gottesman RF, Mosley TH, Alonso A. Association of left ventricular hypertrophy with cognitive decline and dementia risk over 20 years: the Atherosclerosis Risk In Communities-Neurocognitive Study (ARIC-NCS). Am Heart J 2018;204:58-67. 
90. Moazzami K, Ostovaneh MR, Ambale Venkatesh B, Habibi M, Yoneyama $\mathrm{K}$, Wu C, et al. Left ventricular hypertrophy and remodeling and risk of cognitive impairment and dementia: MESA (Multi-Ethnic Study of Atherosclerosis). Hypertension 2018;71:429-436.

91. Williams B, Mancia G, Spiering W, Agabiti Rosei E, Azizi M, Burnier M, et al. 2018 ESC/ESH Guidelines for the management of arterial hypertension. Eur Heart J 2018;39:3021-3104.

92. Pierdomenico SD, Cuccurullo F. Risk reduction after regression of echocardiographic left ventricular hypertrophy in hypertension: a meta-analysis. Am J Hypertens 2010;23:876-881.
93. Okin PM, Devereux RB, Jern $\mathrm{S}$, Kjeldsen $\mathrm{SE}$, Julius $\mathrm{S}$, Nieminen $M S$, et al. Regression of electrocardiographic left ventricular hypertrophy during antihypertensive treatment and the prediction of major cardiovascular events. JAMA 2004;292:23432349.

94. SPRINT MIND Investigators for the SPRINT Research Group, Nasrallah IM, Pajewski NM, Auchus AP, Chelune G, Cheung AK, et al. Association of intensive vs standard blood pressure control with cerebral white matter lesions. JAMA 2019;322:524534. 


\section{Supplementary methods}

\section{Search algorithm}

Our literature search was performed for titles, abstracts and keywords on three databases (Medline, Scopus, Cochrane) using the following combination of search terms (algorithm):

(((cerebral OR brain) AND ( microangiopathy OR micro-angiopathy OR microvessel OR "small vessel" OR small-vessel OR microvascular OR microbleed* OR microhemorrhage* OR dotlike hemosiderin OR leukoaraiosis OR "Virchow-Robin" OR (perivascular AND space*) OR ((lacunar OR lacunae OR lacunes) AND (infarct* OR stroke*)))) OR ("white matter" AND (disease $O R$ diseases $O R$ hyperintensit* $O R$ lesion $O R$ lesions)))

\section{AND}

(((cardiac OR cardio OR heart $O R$ ventricular $O R$ ventricle $O R$ myocardium OR myocardial) AND (mass OR hypertrophy OR hypertrophic $O R$ thickened $O R$ thickening $O R$ enlargement $O R$ enlarged)) OR LVMI OR LVM)

The search was originally performed in the Medline (through PubMed) database on 23 May 2018 and was then updated on 28 December 2019 with the additional inclusion of the Scopus and Cochrane databases. The search yielded a total of 1,959 articles (PubMed, 798; Scopus, 1,113; Cochrane, 57), which were reduced to 1,456 after removing the duplicates. Thus, 1,456 unique titles derived through our search were cumulatively screened for eligibility. Articles derived through the search were sorted by publication date.

\section{Statistical analysis}

We performed random-effect meta-analysis to pool our data. Our main approach utilized the DerSirmonian and Laird (DL) method for calculation of the between-study variance, the estimate of the combined effect for heterogeneity via the Mantel-Haenszel method and the calculation of confidence intervals $(\mathrm{Cl})$ with the Wald-type normal distribution. ${ }^{37}$ This standard approach is currently the most widely used. ${ }^{38}$ However, for our main analyses, we also sought to perform four additional approaches, in order to confirm the robustness of our findings:

(1) We used the Paule-Mandel (PM) estimator (equivalent to the Empirical Bayes [EB] estimator ${ }^{39}$ ) to calculate the betweenstudy variance. It has been shown that the PM estimator performs better than the $D L$, mainly when heterogeneity increases; in those cases it approximates $\mathrm{T}^{2}$ better than the $\mathrm{DL}^{40}$ Additionally, despite it being an iterative method, it has been mathematically proven that convergence of the iteration process al- ways occurs. $^{34}$

(2) We used the (original) Hartung-Knapp (HK) method (also known as Hartung-Knapp-Sidik-Jonkman [HKSJ] method ${ }^{41}$ ) to calculate the overall effect $\mathrm{Cl}$. This method utilizes a modification factor (q) that is used to multiply the overall effect variance and then provides the $\mathrm{Cl}$ via a $t$-distribution. It has been shown to perform better than the standard approach in many instances. ${ }^{38,42}$ However, there are several concerns regarding the use of this method. For instance, when few $(\leq 5)$ studies are pooled the method may be too conservative. ${ }^{37,38}$ Additionally, in those cases the implications of using the modification factor for any given meta-analysis are hard to predict. ${ }^{43}$ On the contrary, in instances where heterogeneity is very low, the method may produce a $\mathrm{Cl}$ that is counterintuitively narrower than the standard approach. ${ }^{41,43,44}$

(3) In order to specifically address this last issue, a modification to the HK method has been proposed by Knapp and Hartung $_{1}{ }^{36}$ termed here $\mathrm{mHK}$. We used the mHK approach to calculate the overall effect $\mathrm{Cl}$ as our 3rd approach. In this method the multiplicative term of $\mathrm{HK}$ is constrained at $\mathrm{q} \geq 1$. This forces the $\mathrm{Cl}$ to be at least as wide as in the standard approach. Use of the mHK method has been supported, mainly when few studies are pooled and the involved standard errors vary. ${ }^{41}$ However, when very few studies are pooled, the method is overly conservative and leads to significant loss in power. ${ }^{43}$ As such, many have suggested various other modification methods in order to better refine the HK method, which will not be discussed here. ${ }^{43,45}$

(4) Finally, we simultaneously used the PM estimator along with the HK method. The PM iteration process attempts to find a positive $\mathrm{T}^{2}$ such that $\mathrm{q}=1 .{ }^{36} \mathrm{It}$ is therefore apparent that if the PM estimator of $\tau^{2}$ is in fact positive, then $q=1$ and the $H K$ modification will produce no effect on the overall effect variance. ${ }^{36,37}$ Therefore this approach is comparable to approach (1) with the exception that it utilizes a $t$-distribution, instead of the normal. This is often beneficial, as it has been shown that for a small $(<16)$ number of pooled studies the $t$-distribution performs better in terms of coverage than the normal. ${ }^{46}$ However, this method becomes overly conservative as the number of studies decreases. If, on the other hand, $\tau^{2}$ is negative in the first cycle of the PM iteration, then the process stops, $\tau^{2}$ is set at 0 and $q$ is calculated at a value $<1 .{ }^{36,41}$ In that special case, applying the HK modification will result in a quantitatively smaller overall effect variance (than that of approach 1), potentially producing a narrower $\mathrm{Cl}$ (than that of approach 1). 
Supplementary Table 1. Management of the quality scoring criteria of the cohort subscale of the Newcastle-Ottawa assessment scale for the purposes of the current study*

\begin{tabular}{|c|c|c|c|c|c|c|c|c|c|}
\hline & \multicolumn{4}{|c|}{ Selection } & \multicolumn{2}{|c|}{ Comparability } & \multicolumn{3}{|c|}{ Outcome } \\
\hline & $\begin{array}{l}\text { Representa- } \\
\text { tiveness of the } \\
\text { exposed } \\
\text { cohort }\end{array}$ & $\begin{array}{l}\text { Selection of } \\
\text { the non- } \\
\text { exposed } \\
\text { cohort }\end{array}$ & $\begin{array}{l}\text { Ascertain- } \\
\text { ment of } \\
\text { exposure }\end{array}$ & $\begin{array}{c}\text { Exclusion of outcome } \\
\text { presence at start of } \\
\text { study }\end{array}$ & $\begin{array}{l}\text { Compara- } \\
\text { bility for } \\
\text { age }\end{array}$ & $\begin{array}{c}\text { Comparability for } \\
\text { hypertension }\end{array}$ & $\begin{array}{l}\text { Assessment of } \\
\text { outcome }\end{array}$ & $\begin{array}{l}\text { Length of } \\
\text { follow-up }\end{array}$ & $\begin{array}{l}\text { Adequacy of } \\
\text { follow-up }\end{array}$ \\
\hline $\begin{array}{l}\text { Point awarded } \\
\text { if... }\end{array}$ & $\begin{array}{l}\text { General popu- } \\
\text { lation-based } \\
\text { study }\end{array}$ & $\begin{array}{l}\text { Drawn from } \\
\text { the same } \\
\text { commu- } \\
\text { nity as } \\
\text { the ex- } \\
\text { posed co- } \\
\text { hort }\end{array}$ & $\begin{array}{l}\text { 1. For LVH: } \\
\text { method } \\
\text { and cri- } \\
\text { teria } \\
\text { used are } \\
\text { reported } \\
\text { 2. For } \\
\text { LVM(I): } \\
\text { method } \\
\text { and } \\
\text { equa- } \\
\text { tions } \\
\text { used are } \\
\text { reported }\end{array}$ & $\begin{array}{l}\text { 1. Cohort studies in } \\
\text { which the outcome } \\
\text { addressed is as- } \\
\text { sessed at baseline } \\
\text { and either subjects } \\
\text { with the outcome } \\
\text { are excluded from } \\
\text { the study or the in- } \\
\text { crement of the out- } \\
\text { come is assessed } \\
\text { 2. Cohort studies in } \\
\text { which the outcome } \\
\text { is "lacunar stroke" } \\
\text { and subjects with } \\
\text { stroke (self-reported, } \\
\text { medical file or imag- } \\
\text { ing ascertained) are } \\
\text { excluded at baseline }\end{array}$ & $\begin{array}{l}\text { Any age } \\
\text { adjust- } \\
\text { ment }\end{array}$ & $\begin{array}{l}\text { 1. In hyperten- } \\
\text { sive patient- } \\
\text { based studies: } \\
\text { adjustment for } \\
\text { hypertension } \\
\text { duration } \\
\text { 2. In all other } \\
\text { studies: any of } \\
\text { the adjust- } \\
\text { ments; SBP, } \\
\text { DBP, anti-hy- } \\
\text { pertensive drug } \\
\text { usage, duration } \\
\text { of hypertension }\end{array}$ & $\begin{array}{l}\text { 1. For dichoto- } \\
\text { mous, scaled } \\
\text { and continuous } \\
\text { outcomes: crite- } \\
\text { ria/method of } \\
\text { quantification } \\
\text { used are report- } \\
\text { ed } \\
\text { 2. For the outcome } \\
\text { "lacunar stroke": } \\
\text { relevant clinical } \\
\text { presentation and } \\
\text { criteria used for } \\
\text { lacunar stroke } \\
\text { identification } \\
\text { are reported }\end{array}$ & $\begin{array}{l}\text { Cohort stud- } \\
\text { ies with } \\
\geq 36 \text { mo } \\
\text { mean fol- } \\
\text { low-up } \\
\text { length }\end{array}$ & $\begin{array}{l}\text { Cohort stud- } \\
\text { ies with } \\
\geq 80 \% \text { of } \\
\text { participants } \\
\text { examined } \\
\text { at baseline } \\
\text { not lost to } \\
\text { follow-up } \\
\text { at end- } \\
\text { point }\end{array}$ \\
\hline $\begin{array}{l}\text { Point not } \\
\text { awarded if... }\end{array}$ & $\begin{array}{l}\text { High-risk pop- } \\
\text { ulation- } \\
\text { based study } \\
\text { (hyperten- } \\
\text { sive, stroke } \\
\text { patients etc.) }\end{array}$ & $\begin{array}{l}\text { 1. Drawn } \\
\text { from a } \\
\text { different } \\
\text { source } \\
\text { 2. No de- } \\
\text { scription } \\
\text { of the } \\
\text { derivation } \\
\text { of the } \\
\text { non-ex- } \\
\text { posed co- } \\
\text { hort }\end{array}$ & $\begin{array}{l}\text { 1. Self-re- } \\
\text { ported } \\
\text { 2. Method } \\
\text { and/or } \\
\text { criteria } \\
\text { used not } \\
\text { reported }\end{array}$ & $\begin{array}{l}\text { 1. Cross-sectional } \\
\text { studies } \\
\text { 2. Cohort studies } \\
\text { which do not fulfil } \\
\text { the above criteria }\end{array}$ & $\begin{array}{l}\text { No age } \\
\text { adjust- } \\
\text { ment }\end{array}$ & $\begin{array}{l}\text { No hypertension } \\
\text { adjustment or } \\
\text { does not fulfil } \\
\text { above criteria }\end{array}$ & $\begin{array}{l}\text { 1. Self-reported } \\
\text { 2. Method of as- } \\
\text { sessment not } \\
\text { reported } \\
\text { 3. Defining lacu- } \\
\text { nes in the con- } \\
\text { text of silent } \\
\text { brain infarcts } \\
\text { including not } \\
\text { only lacunes but } \\
\text { also some } \\
\text { (<20\%) larger } \\
\text { cortical infarcts }\end{array}$ & $\begin{array}{l}\text { 1. Cross-sec- } \\
\text { tional stud- } \\
\text { ies } \\
\text { 2. Cohort } \\
\text { studies } \\
\text { with }<36 \\
\text { mo mean } \\
\text { follow-up } \\
\text { length }\end{array}$ & $\begin{array}{l}\text { 1. Cross-sec- } \\
\text { tional stud- } \\
\text { ies } \\
\text { 2. Cohort } \\
\text { studies } \\
\text { with }<80 \% \\
\text { of baseline } \\
\text { participants } \\
\text { following- } \\
\text { up at end- } \\
\text { point or } \\
\text { follow-up } \\
\% \text { not re- } \\
\text { ported }\end{array}$ \\
\hline
\end{tabular}

LVH, left ventricular hypertrophy; LVM(I): left ventricular mass (index); SBP, systolic blood pressure; DBP, diastolic blood pressure.

*The only case-control study included in out review (Pirinen et al., ${ }^{74}$ 2017) was also graded according to this scale.

Supplementary Table 2. Number of articles excluded after screening the full-text by reason

Reasons for exclusion No. of articles

Cardiac parameters were measured (ECG, TTE) but LVH or LVM(I) were not assessed 22

Article not presenting relevant quantitative data- author contacted but did not reply

Stroke studies where the comparison group consisted of patients with non-lacunar stroke

Article not presenting relevant quantitative data- author was contacted but data was unavailable

Study population not eligible (miscellaneous neurologic diagnoses, dementia, primary cardiomyopathies, etc.)

Articles exploring silent infarcts not including predominantly lacunes (silent cortical infarcts $>20 \%$ )

All participants in the study fulfilling diagnostic criteria for LVH

9

Outcome assessed was not relevant (i.e., brain atrophy)

Studies with inappropriate comparison group (i.e., comparisons between subjects with different CMBs subtypes)

Study protocol: study not yet published

Total articles excluded

9
6
6
5
4
4
2
1
1
60

ECG, electrocardiogram; TTE, transthoracic echocardiogram; LVH, left ventricular hypertrophy; LVM(I), left ventricular mass (index); CMB, cerebral microbleed. 
Supplementary Table 3. Results of the assessment of potential population overlap between the studies meeting eligibility criteria

\begin{tabular}{|c|c|c|c|c|c|c|}
\hline Study & Study name (if reported) & Recruitment period & $\begin{array}{l}\text { Geographical region of } \\
\text { participants recruitment }\end{array}$ & $\begin{array}{l}\text { Total no. rele- } \\
\text { vant to our } \\
\text { meta-analysis }\end{array}$ & $\begin{array}{l}\text { Outcome } \\
\text { examined }\end{array}$ & Overlapping status \\
\hline $\begin{array}{l}\text { Bezerra et al. } \\
(2012)^{50}\end{array}$ & $\begin{array}{l}\text { Atherosclerotic Risk in Commu- } \\
\text { nities Study (ARIC) }\end{array}$ & $\begin{array}{l}\text { 1993-1995 } \\
\text { Sample of 3rd ARIC } \\
\text { visit }\end{array}$ & $\begin{array}{l}\text { Forsyth County (NC) and } \\
\text { Jackson (MS), US }\end{array}$ & 1,827 & Lacunes & $\begin{array}{l}\text { Excluded. Overlap with Jo- } \\
\text { hansen et al. }(2018)^{21}\end{array}$ \\
\hline $\begin{array}{l}\text { Butenaerts et al. } \\
(2016)^{53}\end{array}$ & NR & 2014 & $\begin{array}{l}\text { Jagiellonian University, } \\
\text { Krakow, Poland }\end{array}$ & 155 & WMHs & No \\
\hline $\begin{array}{l}\text { Cermakova et al. } \\
(2017)^{54}\end{array}$ & $\begin{array}{l}\text { Coronary Artery Risk Develop- } \\
\text { ment in Young Adults (CARDIA) }\end{array}$ & $\begin{array}{l}1990 \\
\text { 5th follow-up visit }\end{array}$ & $\begin{array}{l}\text { Birmingham (AL), } \\
\text { Minneapolis (MN), } \\
\text { Oakland (CA), US }\end{array}$ & 627 & WMHs & No \\
\hline $\begin{array}{l}\text { Das et al. } \\
(2008)^{56}\end{array}$ & $\begin{array}{l}\text { Framingham Offspring Study } \\
\text { (FOS) }\end{array}$ & $\begin{array}{l}1996-1998 \\
\text { 6th FOS examina- } \\
\text { tion }\end{array}$ & $\begin{array}{l}>80 \% \text { from New } \\
\text { England, US }\end{array}$ & 2,040 & Lacunes & $\begin{array}{l}\text { Eligible. Overlap with } \\
\text { Jeerakathil et al. (2004), } \\
\text { different outcome }\end{array}$ \\
\hline $\begin{array}{l}\text { Davis et al. } \\
(1998)^{57}\end{array}$ & $\begin{array}{l}\text { Systolic Hypertension in the } \\
\text { Elderly Program (SHEP) }\end{array}$ & 1985-1988 & $\begin{array}{l}\text { Mass mailing and } \\
\text { community screening } \\
\text { (random), US }\end{array}$ & 4,736 & $\begin{array}{l}\text { Lacunar } \\
\text { stroke }\end{array}$ & No \\
\hline $\begin{array}{l}\text { Ferreira et al. } \\
(2017)^{58}\end{array}$ & $\begin{array}{l}\text { Vascular Alteration and Evolu- } \\
\text { tion of Cognitive Impairment } \\
\text { Study-2 (ADELAHYDE-2) }\end{array}$ & 2003-2005 & Nancy, France & 131 & WMHs & No \\
\hline $\begin{array}{l}\text { Fox et al. } \\
(2005)^{59}\end{array}$ & $\begin{array}{l}\text { Atherosclerotic Risk in Commu- } \\
\text { nities Study (ARIC) }\end{array}$ & $\begin{array}{l}\text { 1993-1994 } \\
\text { Sample of 3rd ARIC } \\
\text { visit }\end{array}$ & Jackson (MS), US & 667 & WMHs & $\begin{array}{l}\text { Eligible. Overlap with } \\
\text { Johansen et al. }(2018)^{21} \\
\text { data not meta-analysed } \\
\text { together }\end{array}$ \\
\hline $\begin{array}{l}\text { Görner et al. } \\
(2007)^{60}\end{array}$ & NR & 2003-2004 & Leuven, Belgium & 199 & CMBs & No \\
\hline $\begin{array}{l}\text { Haring et al. } \\
(2017)^{61}\end{array}$ & $\begin{array}{l}\text { Cerebrovascular Disease and Its } \\
\text { Consequences in American } \\
\text { Indians Study (CDCAI), based } \\
\text { on the Strong Heart Study } \\
\text { (SHS) }\end{array}$ & $\begin{array}{l}\text { 1993-1995 } \\
\text { 2nd SHS visit was } \\
\text { used for TTE } \\
\text { measurements }\end{array}$ & $\begin{array}{l}\text { Arizona (AZ), Oklahoma } \\
\text { (OK), North Dakota } \\
\text { (ND) and South Dakota } \\
\text { (SD), US }\end{array}$ & 721 & WMHs & No \\
\hline $\begin{array}{l}\text { Hénon et al. } \\
(1996)^{62}\end{array}$ & NR & 1991-1993 & Lille, France & 610 & WMHs & $\begin{array}{l}\text { Eligible. Overlap with } \\
\text { Mounier-Vehier et al. } \\
(1993)_{1}^{73} \text { different outcome }\end{array}$ \\
\hline $\begin{array}{l}\text { Henskens et al. } \\
(2009)^{63}\end{array}$ & NR & 2004-2006 & Maastricht, Netherlands & 192 & $\begin{array}{r}\text { WMHs, } \\
\text { CMBs }\end{array}$ & No \\
\hline $\begin{array}{l}\text { Hirose et al. } \\
\qquad(2011)^{64}\end{array}$ & Ohasama study & 1998 & Ohasama, Japan & 659 & $\begin{array}{r}\text { Lacunes, } \\
\text { WMHs }\end{array}$ & No \\
\hline $\begin{array}{l}\text { Ikeda et al. } \\
\quad(1994)^{65}\end{array}$ & NR & 1991-1992 & Shizuoka, Japan & 249 & Lacunes & No \\
\hline $\begin{array}{l}\text { Jeerakathil et al. } \\
(2004)^{66}\end{array}$ & $\begin{array}{l}\text { Framingham offspring Study } \\
\text { (FOS) }\end{array}$ & $\begin{array}{l}1991-1995 \\
\text { 5th FOS examina- } \\
\text { tion }\end{array}$ & $\begin{array}{l}>80 \% \text { from New } \\
\text { England, US }\end{array}$ & 1,814 & WMHs & $\begin{array}{l}\text { Eligible. Overlap with Das et } \\
\text { al. (2008), }{ }^{56} \text { different } \\
\text { outcome }\end{array}$ \\
\hline $\begin{array}{l}\text { Johansen et al. } \\
(2018)^{21}\end{array}$ & $\begin{array}{l}\text { Atherosclerotic Risk in Commu- } \\
\text { nities Study (ARIC) }\end{array}$ & $\begin{array}{l}\text { 2011-2013 } \\
\text { 5th ARIC visit }\end{array}$ & $\begin{array}{l}\text { Washington County } \\
\text { (MD), Forsyth County } \\
\text { (NC), Minneapolis } \\
\text { (MN) and Jackson } \\
\text { (MS), US }\end{array}$ & 1,665 & $\begin{array}{r}\text { Lacunes, } \\
\text { WMHs }\end{array}$ & $\begin{array}{l}\text { Eligible. See other ARIC } \\
\text { studies }\end{array}$ \\
\hline $\begin{array}{l}\text { Kawamoto et al. } \\
(1991)^{67}\end{array}$ & NR & NR & Kochi, Japan & 54 & Lacunes & $\begin{array}{l}\text { Eligible. Probable overlap } \\
\text { with Shimada et al. } \\
\text { (1990), }{ }_{17}^{77} \text { different outcome }\end{array}$ \\
\hline $\begin{array}{l}\text { Kohara et al. } \\
(1999)^{68}\end{array}$ & NR & 1992-1998 & Ehime, Japan & 150 & $\begin{array}{r}\text { Lacunes, } \\
\text { WMHs }\end{array}$ & $\begin{array}{l}\text { Eligible. See Kohara et al. } \\
(1997)^{51}\end{array}$ \\
\hline $\begin{array}{l}\text { Kohara et al. } \\
(1997)^{51}\end{array}$ & NR & NR & Ehime, Japan & 100 & Lacunes & $\begin{array}{l}\text { Excluded. Overlap with } \\
\text { Kohara et al. (1999) }\end{array}$ \\
\hline
\end{tabular}


Supplementary Table 3. Continued

\begin{tabular}{|c|c|c|c|c|c|c|}
\hline Study & Study name (if reported) & Recruitment period & $\begin{array}{l}\text { Geographical region of } \\
\text { participants recruitment }\end{array}$ & $\begin{array}{l}\text { Total no. rele- } \\
\text { vant to our } \\
\text { meta-analysis }\end{array}$ & $\begin{array}{l}\text { Outcome } \\
\text { examined }\end{array}$ & Overlapping status \\
\hline $\begin{array}{l}\text { Lee et al. } \\
\qquad(2004)^{69}\end{array}$ & NR & 1998-2000 & Seoul, South Korea & 102 & $\begin{array}{r}\text { WMHs, } \\
\text { CMBs }\end{array}$ & No \\
\hline $\begin{array}{l}\text { Lee et al. } \\
\qquad(2018)^{70}\end{array}$ & NR & 2008-2016 & Seoul, South Korea & 217 & WMHs & No \\
\hline $\begin{array}{l}\text { Longstreth et al. } \\
(1996)^{71}\end{array}$ & $\begin{array}{l}\text { Cardiovascular Health Study } \\
\text { (CHS) }\end{array}$ & 1989-1990 & $\begin{array}{l}\text { Forsyth County (NC), } \\
\text { Sacramento County } \\
\text { (CA), Washington } \\
\text { County (MD) and } \\
\text { Pittsburgh (PA), US }\end{array}$ & 3,301 & WMHs & No \\
\hline $\begin{array}{l}\text { Martinez-Vea et } \\
\text { al. }(2006)^{72}\end{array}$ & NR & NR & Tarragona, Spain & 55 & WMHs & No \\
\hline $\begin{array}{l}\text { Moore et al. } \\
(2018)^{20}\end{array}$ & $\begin{array}{l}\text { Vanderbilt Memory \& Aging } \\
\text { Project }\end{array}$ & 2012-2014 & Nashville (TN), US & 313 & WMHs & No \\
\hline $\begin{array}{l}\text { Mounier-Vehier } \\
\text { et al. }(1993)^{73}\end{array}$ & NR & 1989-1992 & Lille, France & 595 & Lacunes & $\begin{array}{l}\text { Eligible. Overlap with Hénon } \\
\text { et al. (1996), }{ }^{62} \text { different } \\
\text { outcome }\end{array}$ \\
\hline $\begin{array}{l}\text { Nakanishi et al. } \\
(2017)^{22}\end{array}$ & $\begin{array}{l}\text { Subset of the Cardiovascular Ab- } \\
\text { normalities and Brain Lesions } \\
\text { (CABL) Study, based on the } \\
\text { Northern Manhattan Study } \\
\text { (NOMAS) }\end{array}$ & 2005-2010 & Manhattan (NY), US & 665 & $\begin{array}{r}\text { Lacunes, } \\
\text { WMHs }\end{array}$ & No \\
\hline $\begin{array}{l}\text { Ohira et al. } \\
(2006)^{52}\end{array}$ & $\begin{array}{l}\text { Atherosclerosis Risk in Commu- } \\
\text { nities Study (ARIC) }\end{array}$ & $\begin{array}{l}\text { 1987-1989 } \\
\text { 1st ARIC visit }\end{array}$ & $\begin{array}{l}\text { Washington County } \\
\text { (MD), Forsyth County } \\
\text { (NC), Minneapolis } \\
\text { (MN) and Jackson } \\
\text { (MS), US }\end{array}$ & 14,488 & $\begin{array}{l}\text { Lacunar } \\
\text { stroke }\end{array}$ & $\begin{array}{l}\text { Excluded. Overlap with } \\
\text { Johansen et al. (2018) }\end{array}$ \\
\hline $\begin{array}{l}\text { Pirinen et al. } \\
(2017)^{74}\end{array}$ & NR & 1994-2007 & Helsinki, Finland & 237 & $\begin{array}{l}\text { Lacunar } \\
\text { stroke }\end{array}$ & No \\
\hline $\begin{array}{l}\text { Ryu et al. } \\
(2014)^{75}\end{array}$ & NR & 2011-2012 & Multicenter, South Korea & 2,669 & WMHs & No \\
\hline $\begin{array}{l}\text { Selvetella et al. } \\
(2003)^{76}\end{array}$ & NR & $2000-2002$ & Pozzilli, Italy & 195 & Lacunes & No \\
\hline $\begin{array}{l}\text { Shimada et al. } \\
(1990)^{77}\end{array}$ & NR & NR & Kochi, Japan & 34 & WMHs & $\begin{array}{l}\text { Eligible. Probable overlap } \\
\text { with Kawamoto et al. } \\
(1991),{ }^{67} \text { different outcome }\end{array}$ \\
\hline $\begin{array}{l}\text { Sierra et al. } \\
(2002)^{78}\end{array}$ & NR & NR & Barcelona, Spain & 62 & WMHs & No \\
\hline $\begin{array}{l}\text { Tanizaki et al. } \\
(2000)^{79}\end{array}$ & Hisayama Study & 1961 & Hisayama, Japan & 1,621 & $\begin{array}{l}\text { Lacunar } \\
\text { stroke }\end{array}$ & No \\
\hline $\begin{array}{l}\text { van der Veen et } \\
\text { al. }(2015)^{80}\end{array}$ & $\begin{array}{l}\text { Second Manifestations of Arteri- } \\
\text { al Disease-Magnetic Reso- } \\
\text { nance Study (SMART-MR) }\end{array}$ & $2001-2005$ & Utrecht, Netherlands & 663 & $\begin{array}{r}\text { Lacunes, } \\
\text { WMHs }\end{array}$ & No \\
\hline $\begin{array}{l}\text { Vedala et al. } \\
(2019)^{55}\end{array}$ & NR & 2010-2014 & Augusta (GA), US & 167 & WMHs & No \\
\hline
\end{tabular}

US, United States; NR, not reported; WMH, white matter hyperintensity; CMB, cerebral microbleed. 
Supplementary Table 4. Results of the quality assessment of eligible studies according to the cohort subscale of the Newcastle-0ttawa scale

\begin{tabular}{|c|c|c|c|c|}
\hline Study & Selection & Comparability & Outcome & Total score \\
\hline Tanizaki et al. (2000) ${ }^{79}$ & $\star \star \star \star$ & $\star \star$ & $\star \star \star$ & 9 \\
\hline van der Veen et al. $(2015)^{80}$ & $\hbar \star \star \star$ & $\star \star$ & $\star \star \succsim$ & 7 \\
\hline Haring et al. $(2017)^{61}$ & $\star \star \star \star え$ & $\star \star$ & $\star \star$ 约 & 7 \\
\hline Cermakova et al. $(2017)^{54}$ & $\star \star \star \star え$ & $\star \hbar$ & $\star \star \star$ & 7 \\
\hline Davis et al. (1998) ${ }^{57}$ & $\hbar \star \star \star$ & 论场 & $\star \star \star$ & 6 \\
\hline Fox et al. $(2005)^{59}$ & 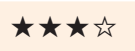 & $\star \star$ & 太动动 & 6 \\
\hline Ferreira et al. (2017) & 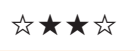 & $\star \star$ & $\star \star \Sigma$ & 6 \\
\hline Johansen et al. $(2018)^{21}$ & $\star \star \star \star \zeta$ & $\star \star$ & 太动动 & 6 \\
\hline Hirose et al. $(2011)^{64}$ & $\star \star \star \star 认$ & $\star \star$ & 太方㑔 & 6 \\
\hline Moore et al. $(2018)^{20}$ & 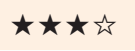 & $\star \star$ & $\star$ 站岤 & 6 \\
\hline Nakanishi et al. (2017) & $\star \star \star \star え$ & $\star \star$ & 太地场 & $6^{*}$ \\
\hline Pirinen et al. $(2017)^{74 t}$ & $认 \star \star 认$ & $\star \star$ & $\star$ 卖弥 & 5 \\
\hline Lee et al. $(2004)^{69}$ & 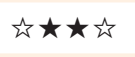 & $\star \star$ & 太论拧 & 5 \\
\hline Butenaerts et al. (2016) ${ }^{53}$ & 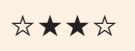 & $\star \star$ & $\star$ 玄方 & 5 \\
\hline Martinez-Vea et al. (2006) ${ }^{72}$ & $认 \star \star 认$ & $\star \star$ & 太论沶 & 5 \\
\hline Jeerakathil et al. $(2004)^{66}$ & $\star \star \star \star ぇ$ & $\star \Sigma$ & 太论柁 & 5 \\
\hline Vedala et al. (2019) 55 & 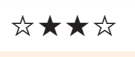 & $\star \star$ & $\star$ 论弥 & 5 \\
\hline Kohara et al. (1999) ${ }^{68}$ & 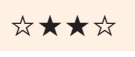 & $\star \varkappa$ & $\star$ 市糸 & 4 \\
\hline Das et al. $(2008)^{56}$ & $\star \star \star \star え$ & $\star$ 放 & 论沵论 & 4 \\
\hline Henskens et al. (2009) & $\succsim \star \star え$ & $\star$ 公 & $\star$ 动拧 & 4 \\
\hline Ryu et al. $(2014)^{75}$ & 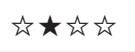 & $\star \star$ & $\star$ 动拧 & 4 \\
\hline Selvetella et al. $(2003)^{76}$ & 光 & 放论 & $\star$ 论弥 & 3 \\
\hline Kawamoto et al. (1991) ${ }^{67}$ & $\succsim \star \star え$ & 论场 & 太方公 & 3 \\
\hline Ikeda et al. (1994) ${ }^{65}$ & 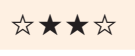 & 论场 & $\star$ 站岤 & 3 \\
\hline Görner et al. $(2007)^{60}$ & 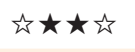 & 论坋 & 太论弥 & 3 \\
\hline Sierra et al. $(2002)^{78}$ & $\succsim \star \star え$ & 计㑔 & $\star$ 施认 & 3 \\
\hline Shimada et al. $(1990)^{77}$ & 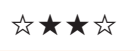 & 论坋 & 太论拧 & 3 \\
\hline Hénon et al. (1996) ${ }^{62}$ & 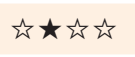 & $\star \hbar$ & $\star$ 计场 & 3 \\
\hline Longstreth et al. (1996) ${ }^{71}$ & 认必放 & $\star$ 动 & 太地场 & 3 \\
\hline Lee et al. $(2018)^{70}$ & 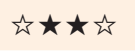 & 放讼 & $\star$ 放拧 & 3 \\
\hline Mounier-Vehier et al. $(1993)^{73}$ & 计太必云 & 论烦 & 论败序 & 1 \\
\hline
\end{tabular}

Selection items include: representativeness of the exposed cohort, selection of the non-exposed cohort, ascertainment of exposure, and exclusion of outcome presence at start of study. Comparability items include: comparability for age and for hypertension. Outcome items include: assessment of outcome, length of follow-up, and adequacy of follow-up cohorts. Articles are sorted in order of decreasing total quality score.

*Only 5 points are scored regarding the outcome "lacunes" due to inadequate assessment of outcome; ${ }^{+}$Case-control study. No point is awarded for the representativeness of the exposed cohort criterion. 
Supplementary Table 5. Alternative random-effect meta-analytical approaches for obtaining pooled OR and 95\% $\mathrm{Cl}$ for the main analyses exploring the associations between left ventricular hypertrophy and lacunes, extensive WMHs and CMBs in general and high risk population studies

\begin{tabular}{|c|c|c|c|c|c|c|c|c|c|}
\hline \multirow{2}{*}{$\begin{array}{l}\text { Random-effect } \\
\text { approach }\end{array}$} & \multicolumn{3}{|c|}{ Lacunes } & \multicolumn{3}{|c|}{ WMHs } & \multicolumn{3}{|c|}{ CMBs } \\
\hline & OR (95\% Cl) & $\tau^{2}$ & $I^{2}, P$ & OR (95\% Cl) & $\tau^{2}$ & $I^{2}, P$ & OR (95\% Cl) & $\tau^{2}$ & $I^{2}, P$ \\
\hline \multicolumn{10}{|l|}{ General population } \\
\hline Main approach & $1.49(1.12-2.00)^{*}$ & 0.0471 & $46 \%, 0.116$ & $1.73(1.38-2.17)^{*}$ & 0 & $0 \%, 0.771$ & - & - & - \\
\hline Alternative approach 1 & $1.49(1.14-1.94)^{*}$ & 0.0323 & $46 \%, 0.116$ & $1.73(1.38-2.17)^{*}$ & 0 & $0 \%, 0.771$ & - & - & - \\
\hline Alternative approach 2 & $1.49(1.03-2.18)^{*}$ & 0.0471 & $46 \%, 0.116$ & $1.73(1.40-2.15)^{*}$ & 0 & $0 \%, 0.771$ & - & - & - \\
\hline Alternative approach 3 & $1.49(0.99-2.26)$ & 0.0471 & $46 \%, 0.116$ & $1.73(1.26-2.39)^{*}$ & 0 & $0 \%, 0.771$ & - & - & - \\
\hline Alternative approach 4 & $1.49(1.02-2.17)^{*}$ & 0.0323 & $46 \%, 0.116$ & $1.73(1.40-2.15)^{*}$ & 0 & $0 \%, 0.771$ & - & - & - \\
\hline \multicolumn{10}{|l|}{ High risk population } \\
\hline Main approach & $2.39(1.32-4.32)^{*}$ & 0.4957 & $70.7 \%, 0.001$ & $2.01(1.45-2.80)^{*}$ & 0.1315 & $53.2 \%, 0.019$ & $2.54(1.04-6.22)^{*}$ & 0.4214 & $67.7 \%, 0.045$ \\
\hline Alternative approach 1 & $2.42(1.16-5.05)^{*}$ & 0.8710 & $70.7 \%, 0.001$ & $2.01(1.45-2.79)^{*}$ & 0.1309 & $53.2 \%, 0.019$ & $2.53(1.02-6.30)^{*}$ & 0.4442 & \\
\hline Alternative approach 2 & $2.39(1.02-5.59)^{*}$ & 0.4957 & $70.7 \%, 0.001$ & $2.01(1.39-2.92)^{*}$ & 0.1315 & $53.2 \%, 0.019$ & 2.54 (0.34-18.78) & 0.4214 & $67.7 \%, 0.045$ \\
\hline Alternative approach 3 & $2.39(1.02-5.59)^{*}$ & 0.4957 & $70.7 \%, 0.001$ & $2.01(1.39-2.92)^{*}$ & 0.1315 & $53.2 \%, 0.019$ & 2.54 (0.34-18.78) & 0.4214 & $67.7 \%, 0.045$ \\
\hline Alternative approach 4 & $2.42(1.00-5.87)^{*}$ & 0.8710 & $70.7 \%, 0.001$ & $2.01(1.39-2.92)^{*}$ & 0.1309 & $53.2 \%, 0.019$ & $2.53(0.34-18.76)$ & 0.4442 & $67.7 \%, 0.045$ \\
\hline
\end{tabular}

Number of studies pooled: lacunes, general population, 5; lacunes, high risk population, 8; WMHs, general population, 5; WMHs, high risk population, 11; $\mathrm{CMBs}$, high risk population, 3. $\tau^{2}$, measuring the extent of variation among the effects observed in different studies (between-study variance), is also provided. $\mathrm{I}^{2}$ is calculated via the Cochran's $Q$ test and the $P$-value is obtained by comparing the statistic with a chi-square distribution with $k-1$ degrees of freedom $(k$, number of studies).

Main approach: DerSirmonian and Laird (DL) method for calculation of the between-study variance, estimate of the combined effect for heterogeneity with the Mantel-Haenszel method, $\mathrm{Cl}$ calculated with Wald-type normal distribution.

Alternative approach 1: use of the Paule-Mandel (PM) estimator (identical to the empirical Bayes [EB] method) for calculation of the between-study variance. Alternative approach 2: use of the (original) Hartung-Knapp (also known as the Hartung-Knapp-Sidik-Jonkman) method (HK or HKSJ) for calculation of the $\mathrm{Cl}$. An overall effect modification factor, $q$, is used to multiply the overall effect variance and the final $\mathrm{Cl}$ is given by a t-distribution.

Alternative approach 3: use of the modified Hartung-Knapp (mHK) method for calculation of the $\mathrm{Cl}$. Here, the modification factor $q$ is constrained at $\geq 1$.

Alternative approach 4: simultaneous use of the PM estimator and the HK method. In cases where $\mathrm{T}^{2}>0, \mathrm{q}=1$; therefore, this approach yields the same overall effect variance as alternative approach 1 , but utilizes a t-distribution (instead of the normal) to calculate the $\mathrm{Cl}$. In the special case of $\mathrm{T}^{2}<0$ (set at 0 ) the overall effect variance is affected (becomes smaller) by the HK method, due to the $q$ being $<1$.

$\mathrm{OR}$, odds ratio; $\mathrm{Cl}$, confidence interval; $\mathrm{WMH}$, white matter hyperintensite; $\mathrm{CMB}$, cerebral microbleed.

${ }^{*}$ Results indicate statistical significance at a two-sided $P<0.05$. 
Supplementary Table 6. Sensitivity analyses by fulfilment of each specific criterion of the cohort subscale of the Newcastle-0ttawa assessment scale for the associations between left ventricular hypertrophy and lacunes, extensive WMHs, CMBs in general and high-risk population studies

\begin{tabular}{|c|c|c|c|c|c|c|}
\hline \multirow{2}{*}{ Variable } & \multicolumn{2}{|r|}{ Lacunes } & \multicolumn{2}{|r|}{ WMH } & \multicolumn{2}{|r|}{$\mathrm{CMB}$} \\
\hline & $\mathrm{k}$ & $\mathrm{OR}(95 \% \mathrm{Cl})$ & k & OR $(95 \% \mathrm{Cl})$ & k & OR (95\% Cl) \\
\hline \multicolumn{7}{|l|}{ General population } \\
\hline Overall analysis & 5 & $1.49(1.12-2.00)^{*}$ & 5 & $1.73(1.38-2.17)^{*}$ & 0 & - \\
\hline \multicolumn{7}{|l|}{ Newcastle-0ttawa scale items } \\
\hline \multicolumn{7}{|l|}{ Selection } \\
\hline Representativeness of the exposed cohort & 5 & $1.49(1.12-2.00)^{*}$ & 5 & $1.73(1.38-2.17)^{*}$ & 0 & - \\
\hline Selection of the non-exposed cohort & 5 & $1.49(1.12-2.00)^{*}$ & 5 & $1.73(1.38-2.17)^{*}$ & 0 & - \\
\hline Ascertainment of exposure & 5 & $1.49(1.12-2.00)^{*}$ & 5 & $1.73(1.38-2.17)^{*}$ & 0 & - \\
\hline Exclusion of outcome presence at start of study & 1 & $1.80(1.25-2.59)^{*}$ & 0 & - & 0 & - \\
\hline \multicolumn{7}{|l|}{ Comparability } \\
\hline Comparability for age & 5 & $1.49(1.12-2.00)^{*}$ & 5 & $1.73(1.38-2.17)^{*}$ & 0 & - \\
\hline Comparability for hypertension & 4 & $1.50(1.09-2.06)^{*}$ & 3 & $1.74(1.34-2.25)^{*}$ & 0 & - \\
\hline \multicolumn{7}{|l|}{ Outcome } \\
\hline Assessment of outcome & 3 & $1.35(0.98-1.87)$ & 5 & $1.73(1.38-2.17)^{*}$ & 0 & - \\
\hline Length of follow-up & 1 & $1.80(1.25-2.59)^{*}$ & 1 & $1.37(0.77-2.44)$ & 0 & - \\
\hline Adequacy of follow-up cohorts & 1 & $1.80(1.25-2.59)^{*}$ & 1 & $1.37(0.77-2.44)$ & 0 & - \\
\hline \multicolumn{7}{|l|}{ High-risk population } \\
\hline Overall analysis & 8 & $2.39(1.32-4.32)^{*}$ & 11 & $2.01(1.45-2.80)^{*}$ & 3 & $2.54(1.04-6.22)^{*}$ \\
\hline \multicolumn{7}{|l|}{ Newcastle-0ttawa scale items } \\
\hline \multicolumn{7}{|l|}{ Selection } \\
\hline Representativeness of the exposed cohort & 0 & - & 0 & - & 0 & - \\
\hline Selection of the non-exposed cohort & 8 & $2.39(1.32-4.32)^{*}$ & 11 & $2.01(1.45-2.80)^{*}$ & 3 & $2.54(1.04-6.22)^{*}$ \\
\hline Ascertainment of exposure & 7 & $2.59(1.36-4.94)^{*}$ & 9 & $2.40(1.56-3.71)^{*}$ & 3 & $2.54(1.04-6.22)^{*}$ \\
\hline Exclusion of outcome presence at start of study & 2 & $0.97(0.27-3.54)$ & 1 & $1.14(0.71-1.82)$ & 0 & - \\
\hline \multicolumn{7}{|l|}{ Comparability } \\
\hline Comparability for age & 3 & $1.51(0.48-4.73)$ & 9 & $1.93(1.37-2.73)^{*}$ & 2 & $3.60(1.54-8.43)^{*}$ \\
\hline Comparability for hypertension & 2 & $0.92(0.27-3.16)$ & 6 & $2.07(1.29-3.33)^{*}$ & 1 & $5.48(2.56-11.75)^{*}$ \\
\hline \multicolumn{7}{|l|}{ Outcome } \\
\hline Assessment of outcome & 7 & $2.59(1.36-4.94)^{*}$ & 11 & $2.01(1.45-2.80)^{*}$ & 3 & $2.54(1.04-6.22)^{*}$ \\
\hline Length of follow-up & 2 & $0.97(0.27-3.54)$ & 2 & $2.90(0.42-19.84)$ & 0 & - \\
\hline Adequacy of follow-up cohorts & 1 & $1.77(0.85-3.70)$ & 0 & - & 0 & - \\
\hline
\end{tabular}

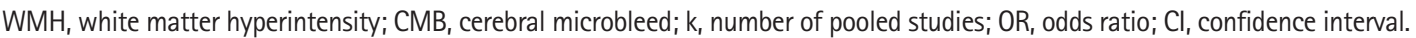

${ }^{*}$ Results indicate statistical significance. 
Study (author, year)

Görner, 2007

Henskens, 2009

Lee, 2004

Overall (I-squared $=67.7 \%, P=0.045)$

NOTE: Weights are from random effects analysis

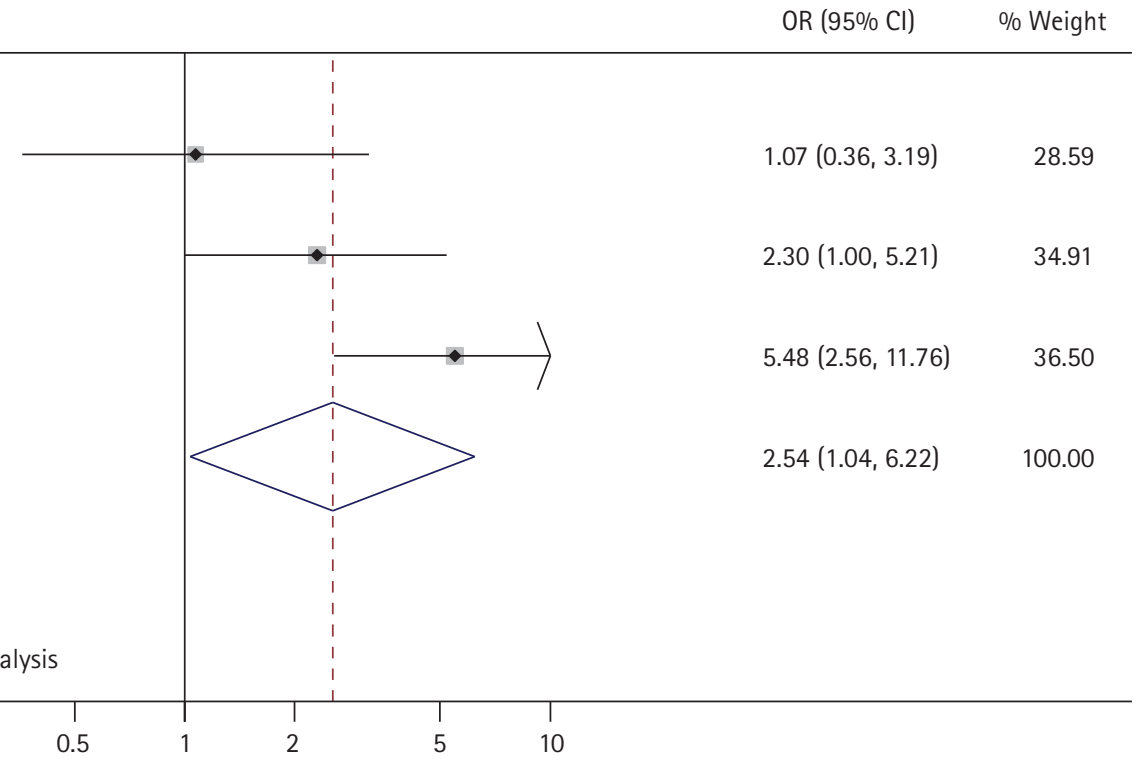

Supplementary Figure 1. Forest plot of the meta-analysis association estimates between left ventricular hypertrophy and cerebral microbleeds in high-risk population studies. Odds ratios (ORs) of each study are depicted as data markers; shaded boxes around the data markers indicate the statistical weight of the respective study; 95\% confidence intervals ( $\mathrm{Cls}$ ) are indicated by the error bars; pooled-effect estimate along with its $95 \% \mathrm{Cl}$ is as a diamond. 


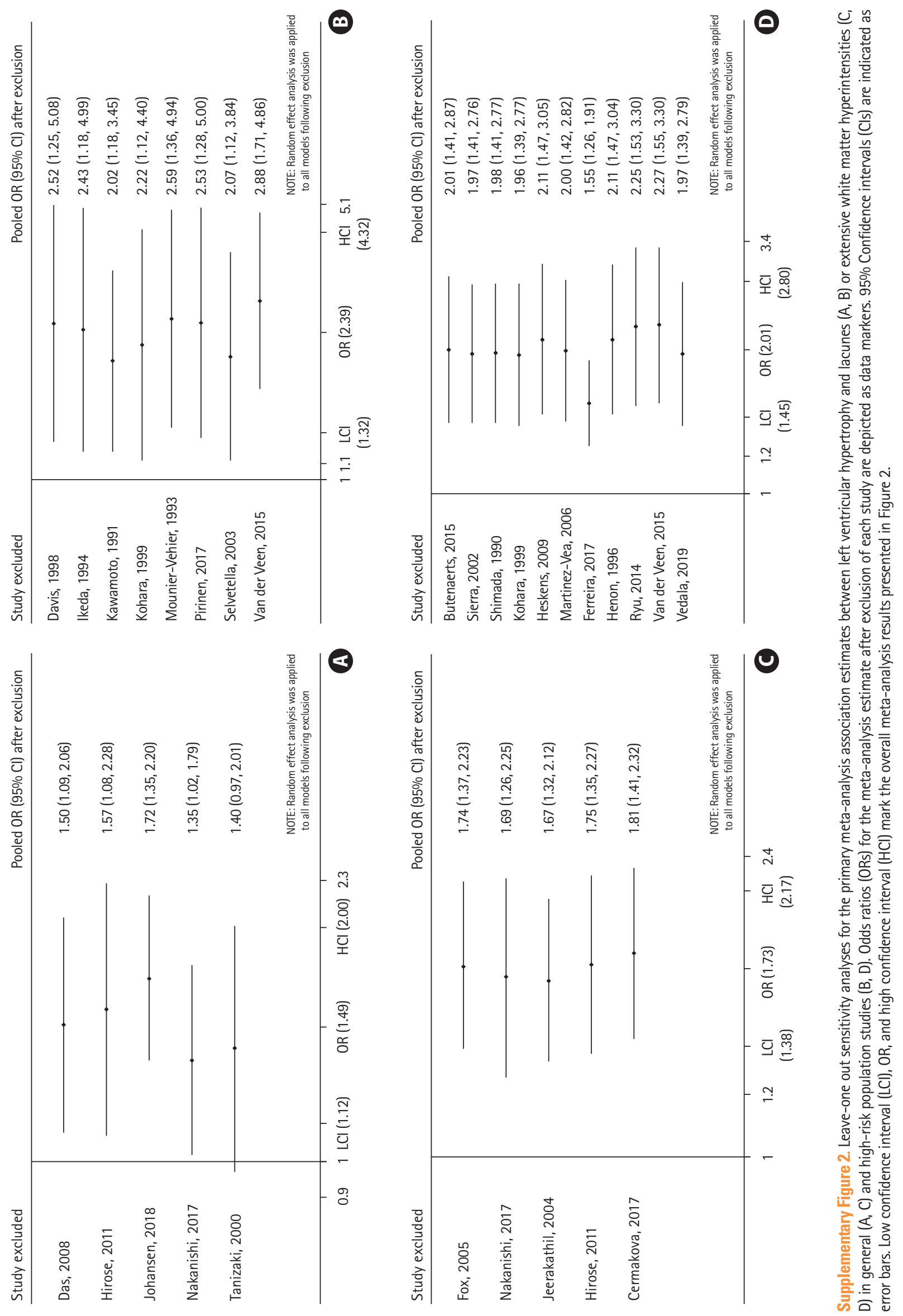


Lacunes, general population.

Funnel plot with pseudo 95\% confidence intervals

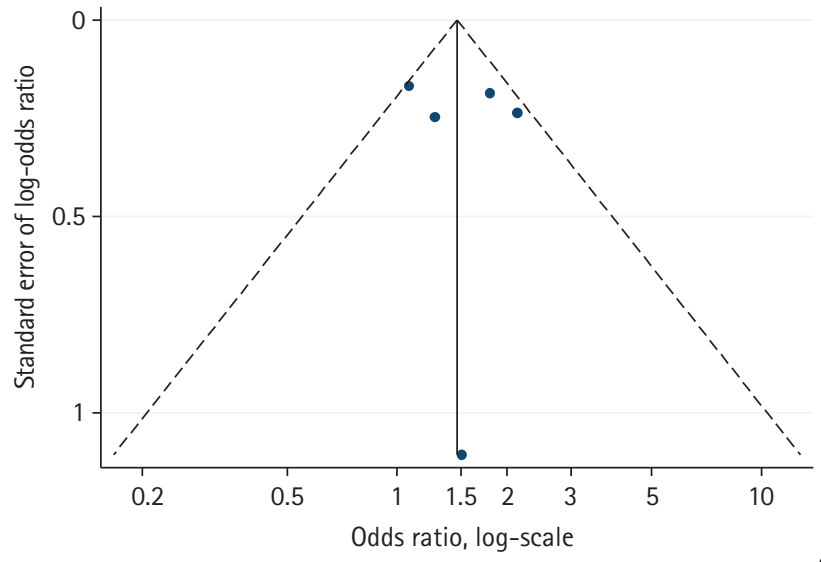

A

WMH's, general population.

Funnel plot with pseudo 95\% confidence intervals

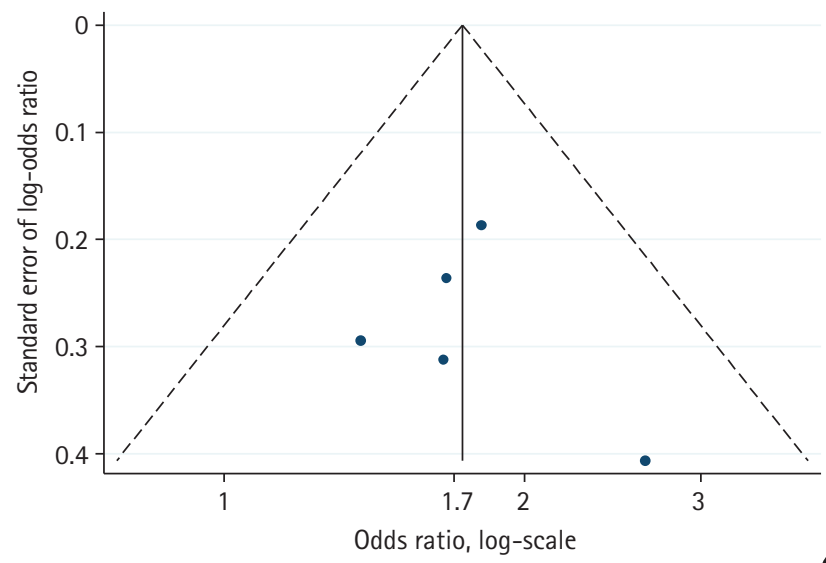

Lacunes, high risk population.

Funnel plot with pseudo 95\% confidence intervals

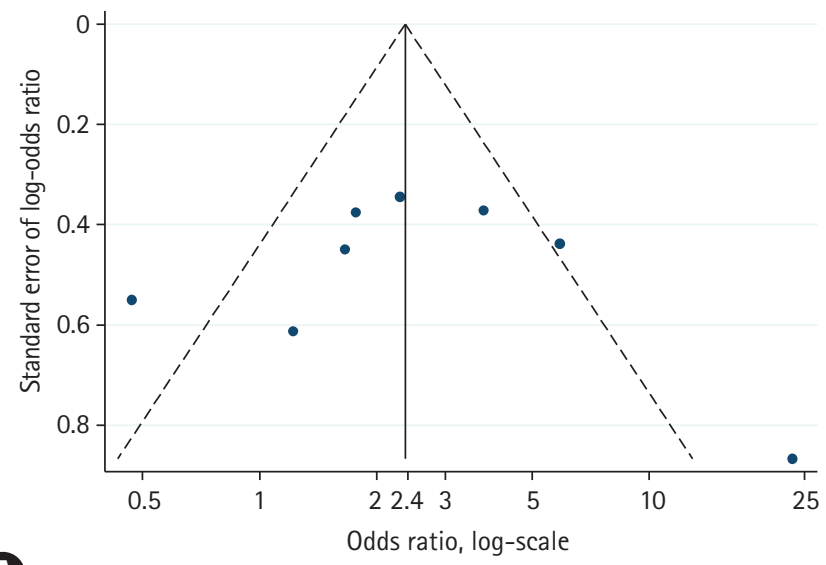

B
WMH's, high risk population. Funnel plot with pseudo 95\% confidence intervals

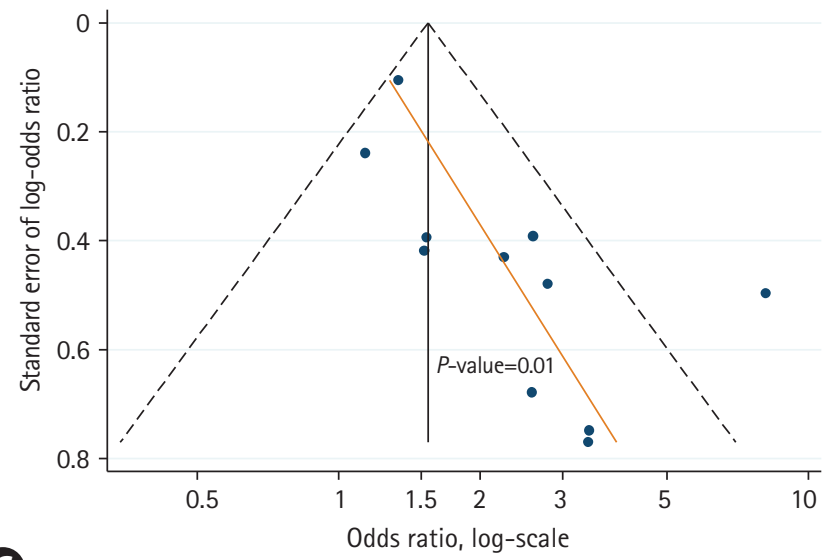

C

Supplementary Figure 3. Funnel plots of the meta-analyses for the associations between left ventricular hypertrophy and lacunes $(A, B)$ or extensive white matter hyperintensities $(C, D)$ in general $(A, C)$ and high-risk population studies $(B, D)$. Each study is depicted as a dot; the black vertical line indicates the overall fixed-effect estimate; pseudo 95\% confidence intervals ( $\mathrm{Cls}$ ) are represented by the dashed lines; in cases where $\geq 10$ studies were pooled, the Egger line is drawn in orange along with its accompanying $P$-value. 
Fill 1

Fill 2

Fill 3

Fill 4

Fill 5

Butenaerts, 2015

Ferreira, 2017

Henon, 1996

Henskens, 2009

Kohara, 1999

Martinez-Vea, 2006

Ryu, 2014

Shimada, 1990

Sierra, 2002

Van der Veen, 2015

Vedala, 2019

Overall (I-squared $=65.9 \%, P=0.000)$

NOTE: Weights are from random effects analysis

0.2

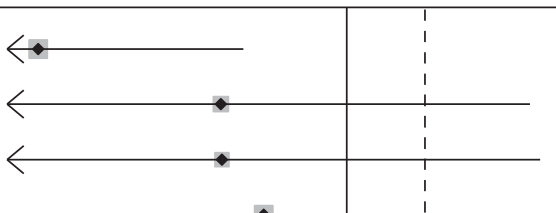

$0.23(0.09,0.61)$

6.01

$0.55(0.13,2.39)$

3.72

$0.55(0.12,2.51)$

3.58

$0.67(0.26,1.73)$

6.22

$0.73(0.34,1.57)$

7.37

$2.25(0.97,5.23)$

6.84

$8.13(3.07,21.53) \quad 6.01$

$1.54(0.71,3.34) \quad 7.33$

$1.52(0.67,3.45) \quad 7.00$

$2.79(1.09,7.14) \quad 6.22$

$2.58(0.68,9.74) \quad 4.24$

$1.34(1.09,1.65) \quad 11.21$

$3.40(0.75,15.39) \quad 3.58$

$3.42(0.79,14.82) \quad 3.72$

$1.14(0.71,1.82) \quad 9.60$

$2.59(1.20,5.58) \quad 7.37$

$1.45(1.03,2.04) \quad 100.00$

WMH's high risk population.

"Trimmed and filled" funnel plot with pseudo 95\% confidence intervals

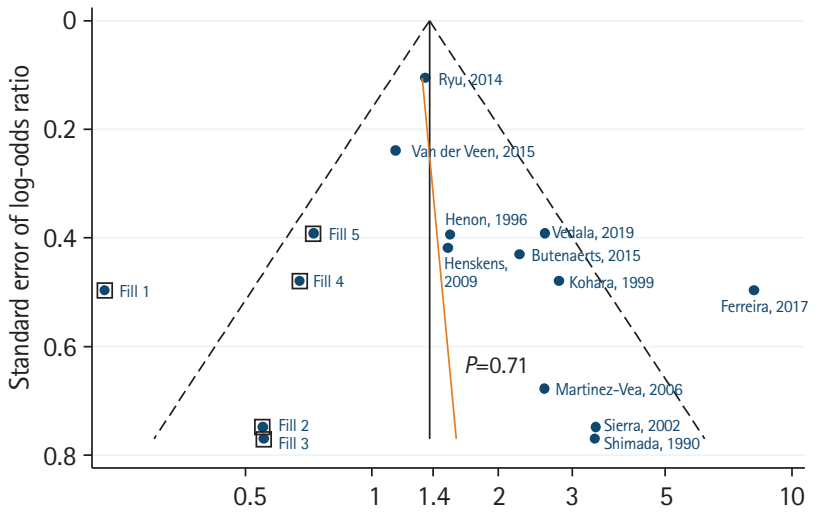

Odds ratio, log-scale

Supplementary Figure 4. "Trim and fill method" (forest and funnel plot) for the association between left ventricular hypertrophy and extensive white matter hyperintensities in high-risk population studies, where significant small study effects were identified with the Egger's method. (A) "Filled" forest plot, (B) "filled" funnel plot; a total of 5 "missing studies" were added, labelled as "Fill 1-5." OR, odds ratio; $\mathrm{Cl}$, confidence interval. 